Portland State University

PDXScholar

\title{
No More Freeways: Urban Land Use-Transportation Dynamics without Freeway Capacity Expansion
}

\author{
Lei Zhang \\ University of Maryland at College Park \\ We Xu \\ Oregon State University
}

Follow this and additional works at: https://pdxscholar.library.pdx.edu/trec_reports

Part of the Transportation Commons, and the Urban Studies Commons Let us know how access to this document benefits you.

\section{Recommended Citation}

Lei Zhang \& We Xu.Title of report. No More Freeways: Urban Land Use Transportation Dynamics Without Freeway Capacity Expansion. OTREC-RR-11-02. Portland, OR: Transportation Research and Education Center (TREC) 2011. http://dx.doi.org/10.15760/trec.100

This Report is brought to you for free and open access. It has been accepted for inclusion in TREC Final Reports by an authorized administrator of PDXScholar. Please contact us if we can make this document more accessible: pdxscholar@pdx.edu. 


\section{SOTREC}

FINAL REPORT

\section{No More Freeways: Urban Land Use Transportation Dynamics Without Freeway Capacity Expansion}

OTREC-RR-11-02 January 2011 



\title{
NO MORE FREEWAYS: URBAN LAND USE- TRANSPORTATION DYNAMICS WITHOUT FREEWAY CAPACITY EXPANSION
}

\author{
Final Report
}

\section{OTREC-RR-11-02}

\author{
by \\ Lei Zhang \\ University of Maryland - College Park \\ Wei Xu \\ Oregon State University
}

for

Oregon Transportation Research

and Education Consortium (OTREC)

P.O. Box 751

Portland, OR 97207

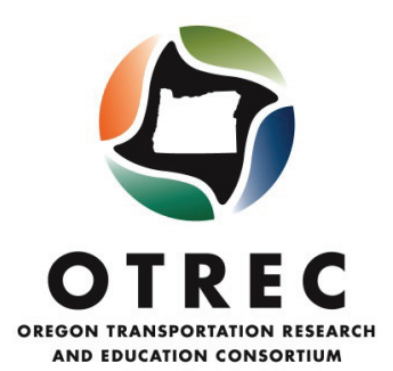

January 2011 



\section{Technical Report Documentation Page}

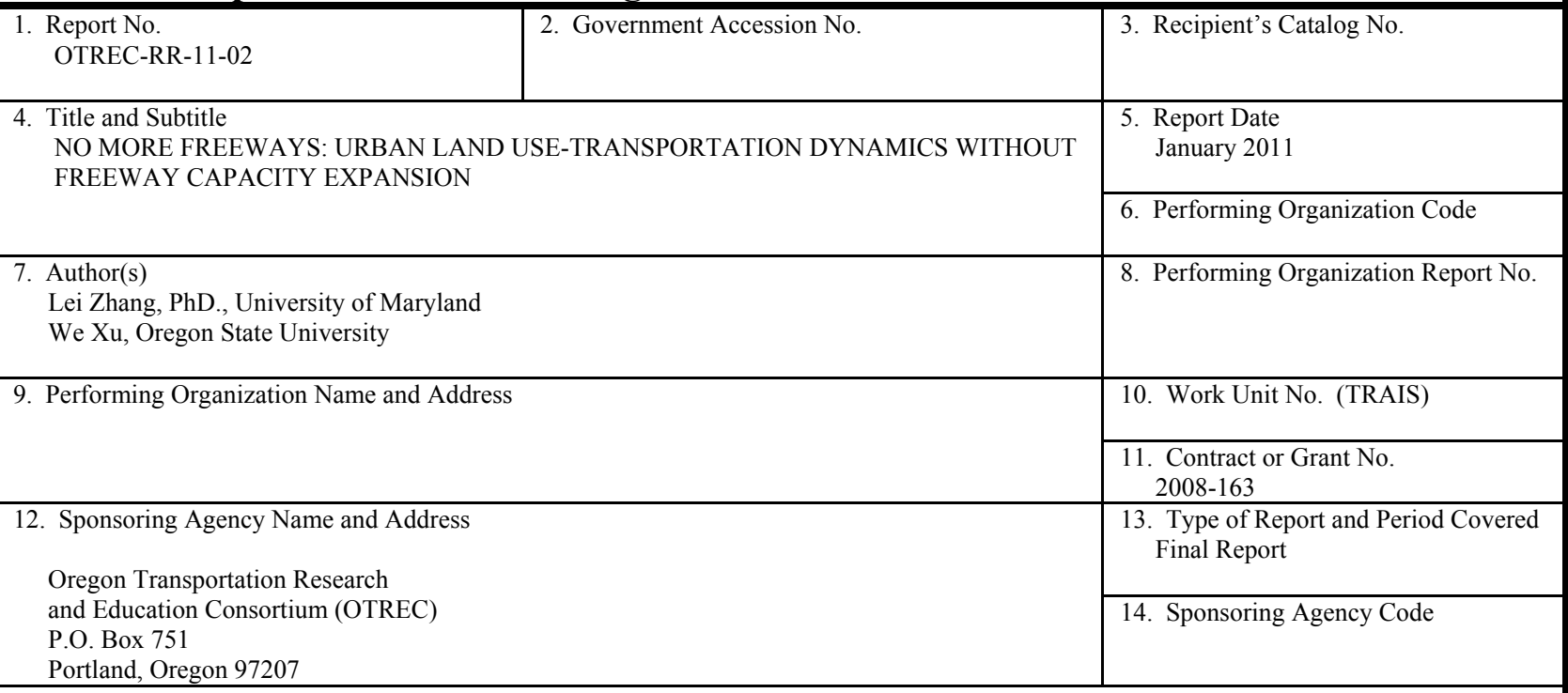

\section{Supplementary Notes}

\section{Abstract}

Observations of the various limitations of freeway capacity expansion have led to a provocative planning and policy question - What if we completely stop building additional freeway capacity. From a theoretical perspective, as a freeway transportation network matures, there exists a saturation point beyond which any additional freeway capacity would only be counterproductive from a welfare point of view, and worsen the existing urban transportation problems. Traditional benefit/cost analysis of individual freeway capacity expansion projects often ignores long-term induced demand and land use changes and does not represent a systems approach to this important theoretical issue. From a practical perspective, a no-more-freeway policy can relieve transportation funds for other potentially more effective usages, such as improving urban arterial street system, improving transit level of service and coverage, implementing demand management and pricing strategies, and facilitating more efficient land use patterns (e.g. high density in-fill and transit-oriented developments).

This research answers the following critical land use-transportation planning questions. Improved knowledge on these issues should benefit planers and decision-makers who pursue mobility and sustainability objectives and have the power to shape future cities.

(1). Under what conditions will freeway capacity expansion become counterproductive to urban planning objectives (where is the saturation point)?

(2). How will land use and transportation evolve under a "No-More-Freeway" policy?

(3). What are the implications of such a policy on congestion, land use efficiency, transportation finance, and social welfare?

(4). What is the impact of a less restrictive "No-More-Freeway" policy that only allows private-section freeway investments and relieves public-section freeway investments for other compelling transportation needs.

The analysis in this project builds upon a modeling tool, ABSOLUTE, developed by the P.I. in previous research projects. ABSOLUTE is an Agent-Based Simulator Of Land Use-Transportation Evolution, which translates planning policies such as the "No-MoreFreeway" policy into alternative urban growth paths and possibly urban growth equilibria (land use and transportation system equilibria). Due to the "Small Start" nature of this OTREC project, the analysis focuses primarily on stylized urban areas, and empirical analysis of the "No-MoreFreeway" policy is only conducted for one policy scenario on the Twin Cities, MN, area.

\section{Key Words}

\section{Distribution Statement}

No restrictions. Copies available from OTREC: www.otrec.us

19. Security Classification (of this report)

Unclassified

20. Security Classification (of this page)
Unclassified

21. No. of Pages 


\section{ACKNOWLEDGEMENTS}

This project was funded by the Oregon Transportation Research and Education Consortium (OTREC).

\section{DISCLAIMER}

The contents of this report reflect the views of the authors, who are solely responsible for the facts and the accuracy of the material and information presented herein. This document is disseminated under the sponsorship of the U.S. Department of Transportation University Transportation Centers Program and OTREC in the interest of information exchange. The U.S. Government and OTREC assume no liability for the contents or use thereof. The contents do not necessarily reflect the official views of the U.S. Government or OTREC. This report does not constitute a standard, specification, or regulation. 


\section{ABSTRACT}

Observations of the various limitations of freeway capacity expansion have led to a provocative planning and policy question: What if we completely stop building additional freeway capacity? From a theoretical perspective, as a freeway transportation network matures there exists a saturation point beyond which any additional freeway capacity would only be counterproductive and would worsen existing urban transportation problems. Traditional benefit/cost analysis of individual capacity-expansion projects often ignores long-term induced demand and land use changes and does not represent a systems approach to this important theoretical issue. From a practical perspective, a "No-More-Freeway" policy can relieve transportation funds for other potentially more effective uses, such as improving urban arterial street systems, improving transit level of service and coverage, implementing demand management and pricing strategies, and facilitating more efficient land use patterns (e.g., highdensity infill and transit-oriented developments).

This research answers the following critical questions related to land use and transportation planning. Improved knowledge on these issues should benefit planners and decision-makers who pursue mobility and sustainability objectives and have the power to shape future cities.

(1) Under what conditions will freeway capacity expansion become counterproductive to urban planning objectives (where is the saturation point)?

(2) How will land use and transportation evolve under a "No-More-Freeway" policy?

(3) What are the implications of such a policy on congestion, land use efficiency, transportation finance and social welfare? 
(4) What is the impact of a less restrictive "No-More-Freeway" policy that only allows private-section freeway investments and relieves public-section freeway investments for other compelling transportation needs?

The analysis in this project builds upon a modeling tool, ABSOLUTE (Agent-Based Simulator Of Land Use-Transportation Evolution), developed by the principal investigator in previous research projects. ABSOLUTE translates planning policies such as the "No-MoreFreeway" policy into alternative urban growth paths and possibly urban growth equilibria (land use and transportation system equilibria). Due to the "small start" nature of this OTREC project, the analysis focuses primarily on stylized urban areas, and empirical analysis of the "No-MoreFreeway" policy is only conducted for one policy scenario in Minnesota's Twin Cities area. 


\section{TABLE OF CONTENTS}

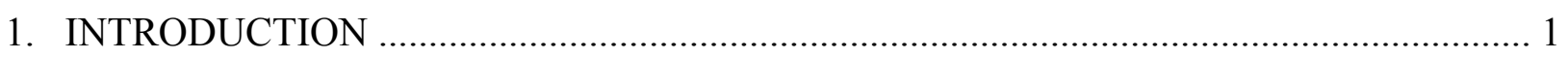

1.1. Why a Study on the "No-More-Freeway" Policy Proposal? ............................... 1

1.2. Research Objectives and Scope ......................................................................... 3

1.3. Organization of the Project Report …....................................................................... 5

2. LITERATURE REVIEW ......................................................... 7

2.1. Transportation Investment in the Urban Transportation Planning Process ................... 9

2.2. Transportation Pricing and Joint Pricing-Investment Analysis ................................. 9

2.3. Transportation Network Ownership Structures .......................................................... 11

2.4. General Modeling Methods for Transportation Economic Analysis ........................... 13

2.5. Transportation and Land Use Growth Models ...................................................... 15

3. THE “ABSOLUTE” MODEL SYSTEM .............................................................. 21

3.1. Transportation - Land Use Growth and the Role of Freeway Investment .................. 21

3.2. Overview of the ABSOLUTE Model System ..................................................... 23

3.3. Accessibility Measures and the Land Use Model .................................................. 26

3.4. Four-Step Travel Demand Model ................................................................................. 30

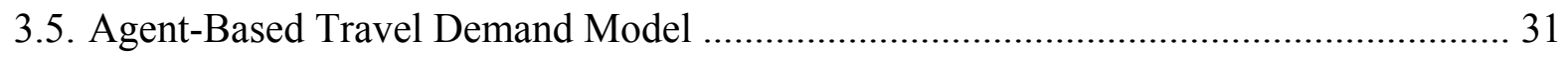

3.5.1. Overview of the Agent-Based Demand Model ............................................ 31

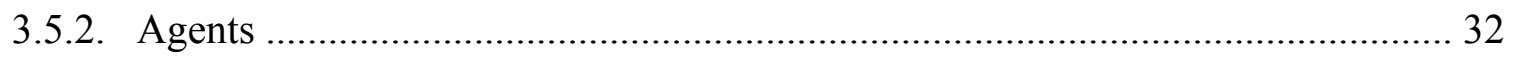

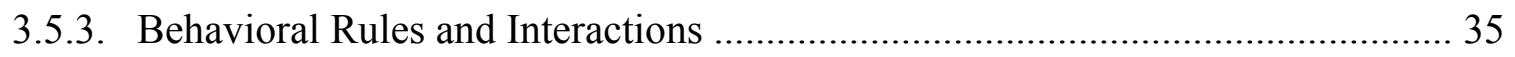

3.6. Discussion on Model Calibration and Validation .................................................... 39

4. MODELING TRANSPORTATION PRICING AND INVESTMENT POLICIES ............. 45

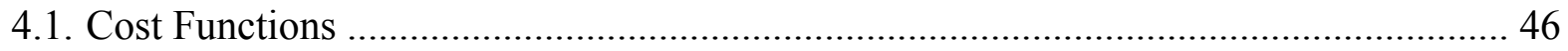

4.2. Pricing and Investment Policies under Public-Sector Ownership ............................. 47

4.2.1. Pricing Policy: Average Cost Pricing .............................................................. 47

4.2.2. Investment Policy: Bottleneck Removal ................................................... 47

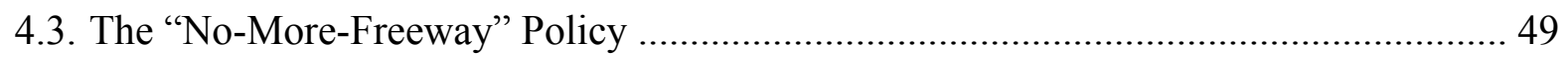

4.4. Pricing and Investment Policies under Private-Sector Ownership ............................. 50

4.4.1. Pricing Policy: Short-Run Profit-Maximizing …........................................ 50

4.4.2. Investment Policy: Long-Run Profit-Maximizing ...................................... 53 
4.5. Pricing and Investment Policies under Mixed Ownership ............................................ 55

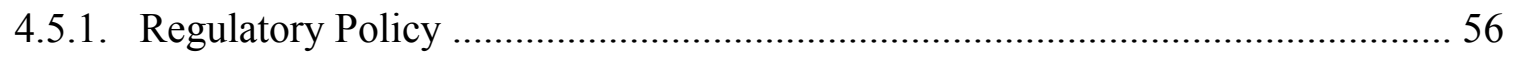

4.5.2. Market Entry of Private Tolled Freeways ............................................................. 56

4.5.3. Investment Policy of Private Toll Roads ........................................................... 59

4.5.4. Pricing Policy of Private Toll Roads ……………………....................................60

4.6. Socially Optimal Pricing and Investment Policies ......................................................... 61

4.6.1. Pricing Rule: Marginal Cost Pricing Scheme ……………………………….... 61

4.6.2. Investment Rule: System-Wide Benefit-Cost Analysis ...................................... 62

5. SIMULATION FINDINGS IN A HYPOTHETICAL URBAN AREA ………….................6 65

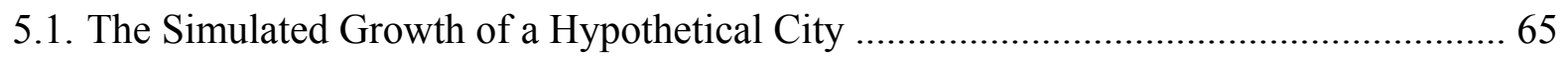

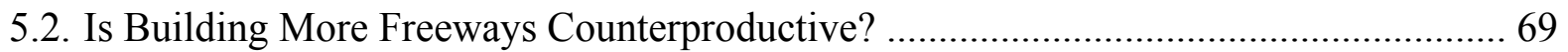

5.3. The Land Use Impact of the "No-More-Freeway" Policy ............................................ 70

6. MORE PUBLIC FREEWAYS, MORE PRIVATE FREEWAYS OR NO MORE FREEWAYS? .. 73

6.1. Five Alternative Policy Scenarios for Twin Cities, MN …………………………....... 73

6.2. Net Social Benefits under Alternative Policy Scenarios ................................................. 75

6.3. Welfare Impact of Private-Sector Freeway Investment ................................................. 78

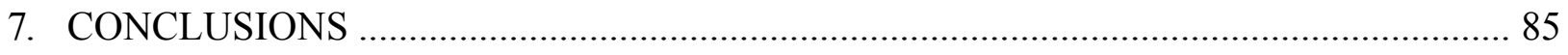

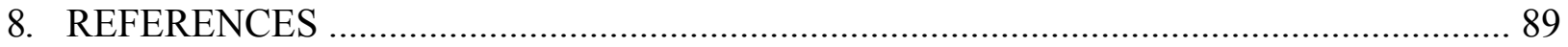




\section{LIST OF TABLES}

Table 3.1. Coefficients in the ABSOLUTE Model .........................................40

Table 6.1. Five Policy Scenarios Tested for Twin Cities .................................... 74 


\section{LIST OF FIGURES}

Figure 3.1. Flowchart of ABSOLUTE Model System .................................................... 24

Figure 3.2. The Sioux-Falls Network (Numbers are Node and Arc Indices) .......................... 41

Figure 3.3: Received and Modeled Travel Time Distributions on the Sioux-Falls Network ..... 42

Figure 4.1. Profit-Maximizing Pricing under Uncertainty ............................................... 52

Figure 5.1. Transportation Network Growth under Different Policies ................................... 66

Figure 5.2. Vehicle Hours Traveled Under Different Policies ............................................... 70

Figure 5.3. Land Use Changes Over Time .................................................................. 72

Figure 6.1. Net Social Benefits of Alternative Policy Scenarios ......................................... 76

Figure 6.2. Year 2020 Location of the New Private Toll Roads ........................................... 79

Figure 6.3. Lane-Km of Private Tolled Freeways and the Average Toll ............................... 81

Figure 6.4. Profitability of Private Tolled Freeways Over Time ........................................... 81 


\section{INTRODUCTION}

\subsection{Why a Study on the "No-More-Freeway" Policy Proposal?}

Transportation networks grow and decline in response to changing travel demand and technology. In 1900, there were 240 kilometers of paved road in the United States (BTS 2002), and this total had increased to 6.4 million by 2000 (Peat 2002). Transportation agencies at the federal, state and local levels are still making routine capacity-expansion decisions to achieve mobility and accessibility objectives. Similarly, population and economic growth tend to impose increasing demand on developable land. Since the 1970s, the urban growth boundary in Portland, OR, has been expanded three dozen times, with five major expansions in the last eight years to accommodate increased population and economic activities. The growth of transportation networks and land use both affect the social and economic activities a region can support and are clearly interrelated. However, the urban land use-transportation growth dynamics have not been fully recognized in capacity-expansion decisions. Planners and decision-makers often are drawn to short-term solutions for prominent freeway bottlenecks.

Urban areas in the U.S. have grown at a fast pace in the last several decades. Many attribute the sprawling land use development pattern to the construction and expansion of limited-access freeways, which initially greatly improved urban mobility but have since experienced deteriorating level of service. Urban traffic congestion is a serious and continuously growing problem in many cities. It is now widely acknowledged that we cannot build our way out of congestion due to induced demand, increasing land acquisition and construction costs, and public opposition. For instance, a recent study (Davis and Sanderson 2001) finds that 1,150 lanemiles of new freeways would be required in the next 20 years to maintain uncongested traffic flow in Minnesota's Twin Cities area. That represents a 70\% expansion of the existing freeway 
system in the Twin Cities, which is an obviously impractical investment scenario. Most U.S. cities are employing a variety of transportation management, multimodal and, to a lesser extent, pricing strategies to maintain/improve urban mobility and accessibility, in addition to traditional freeway capacity expansion.

Land use and transportation decision-makers across the nation are facing a capacityexpansion dilemma. Conventional wisdom appears to suggest that some freeway capacity expansion is necessary to cope with congestion, even when land use and travel demand management strategies are present. Empirical evidence suggests that cities are unlikely to be able to build their way out of congestion. As new freeway capacity attracts even more users, traffic gridlocks persist and attempts to build even more capacity usually become increasingly more difficult and expensive. There are various limitations to freeway capacity expansion in urban areas. As the road network grows, the unit cost of building an extra unit of freeway capacity increases because: (1) land that is cheap and easily acquirable for freeway projects is likely to have already been used for road construction; (2) construction materials, energy and labor costs increase at a much faster pace than the general price index; and (3) building new freeway capacity on an already-mature road network tends to create significant friction between the capacity-expansion projects and the existing built environment. In contrast, the marginal benefit of building additional freeway capacity diminishes over time. Induced demand causes the congestion on newly constructed/expanded freeway sections to reach its pre-construction level within several years. In addition, removing a specific freeway bottleneck with capacity expansion can often create multiple new bottlenecks elsewhere on the road network. A large body of literature in urban planning and integrated land use-transportation planning has blamed freeway capacity expansion for excess travel, urban sprawl, unsustainable transportation options, 
poor quality of life, and all the associated socio-economic issues. Recent research by the P.I. has shown quantitatively that, given the same transportation investment budget, congestion can be more effectively mitigated with a well-connected network of main arterial streets than with a smaller number of freeways (Zhang and Levinson 2005).

In recognition of these limitations, the focus of U.S. transportation investment policies has shifted since the last 1980s from expanding freeway capacity to preserving and improving the efficiency of existing facilities. The cost-effectiveness of freeway capacity expansion in solving today's urban transportation problems (congestion, energy use, environmental impact, sustainability, quality of life, etc.) has become so dubious that certain large urban areas have essentially stopped building new freeway capacity. As a city synonymous with congestion, Los Angeles has not spent a dime in 15 years on expanding freeway capacity. Instead, the city has focused on building carpool lanes, creating a more bike-friendly atmosphere and expanding public transport. Massive expansions to the light-rail and subway system are also on the docket. Following the much criticized Central Artery underground freeway project (better known as the "Big Dig"), the Greater Boston Council of Government has proceeded to adopt a strict "NoMore-Freeway" position with a comprehensive set of transportation management strategies.

\subsection{Research Objectives and Scope}

Understanding how markets and policies translate into transportation facilities and land use development on the ground is essential for both scientific understanding and improving planning/evaluation. This research endeavors to understand the evolutionary growth process of transportation networks and land use in urban areas when a policy restricting freeway capacity expansion is implemented. The main research objective is to show quantitatively the urban 
mobility and land use consequences of not making additional investments in freeway capacity. The research findings may advocate moderate freeway capacity expansion or may oppose all freeway capacity expansion. In either case, an improved understanding of when and why freeway capacity expansion is or is not socially desirable should be obtained.

The effectiveness of the "No-More-Freeway" policy obviously depends on how the capacity-expansion fund is re-allocated (e.g., arterial streets, transit, pricing, carpools, demand management, and incentives for high-density development). Another objective of the research is to assess the alternative use of current freeway-expansion funds (with a focus on arterial street improvement due to time and budget constraints).

This research will answer the following critical questions related to land use and transportation planning with regard to freeway capacity expansion. Improved knowledge on these issues should benefit planners and decision-makers who pursue mobility and sustainability objectives and have the power to shape future cities.

(1) Under what conditions will freeway capacity expansion become counterproductive to urban planning objectives (where is the saturation point)?

(2) How will urban land use and transportation evolve under a "No-More-Freeway" policy?

(3) What are the implications of such a policy on congestion, land use efficiency, transportation finance and social welfare?

(4) What is the impact of a less restrictive "No-More-Freeway" policy that only allows private-section freeway investments and relieves public-section freeway investments for other compelling transportation needs? 
The "small start" nature of the proposed project and the one-year schedule require a limited project scope with clear emphasis. This project focuses on methodology development and demonstration in stylized urban areas (i.e., a hypothetical urban area with a grid transportation network and land use pattern). Empirical testing is conducted only for the Twin Cities metropolitan area without extensive land use model calibration. Future research should seek real-world applications and state/local agency support. Nevertheless, this project provides a valuable proof of the concept that an integrated, urban systems model that considers long-run transportation network and land use changes is feasible for large-scale applications and suitable for the analysis of transportation investment and other planning policies.

\subsection{Organization of the Project Report}

The remainder of this project report is organized as follows: Chapter 2 provides a review of related literature in regional science, urban economics, regional planning and transportation. Though the reviewed studies have dissimilar objectives and methodologies, they all shed light on the nature of land use and transportation network growth and the associated socio-economic impact. Chapter 3 describes the ABSOLUTE model system, which is developed for the analysis of the "No-More-Freeway" policy and other alternative transportation investment policies. In particular, the transportation demand and land use modules are discussed in detail in this chapter. Chapter 4 develops models of various transportation pricing, investment and ownership policies. The "No-More-Freeway" policy is first evaluated for a hypothetical urban area in Chapter 5, followed by a large-scale policy evaluation in Chapter 6. Conclusions and future research directions are offered in Chapter 7. 


\section{LITERATURE REVIEW}

The "No-More-Freeway" proposal is one of many alternative transportation investment policies. Previous research on transportation investment in the urban planning process is reviewed in Section 2.1. An important parameter that drives investment decisions is the amount of transportation revenue, which results from a particular transportation pricing policy and users' responses to the pricing policy. Since the subsequent modeling work in this project develops a joint pricing-investment model to study the impact of "No-More-Freeway" and other policies, Section 2.2 summarizes previous literature on the subject of transportation pricing theories and combined analysis of pricing and investment policies. The subject of transportation facility ownership is also considered in this literature review because we are interested in a less restrictive version of the "No-More-Freeway" policy: no public-sector investment on additional freeway capacity and only private investment on new freeway capacity. Section 2.3 surveys previous studies on transportation network ownership structures, including public, private and mixed ownership. The modeling focus of this project is on the dynamics of urban transportation and land use systems under "No-More-Freeway" and other alternative transportation planning policies. Section 2.4 discusses general modeling methods for transportation investment and economic analysis, followed by a more focused presentation of past modeling work on the evolution of transportation and land use in Section 2.5.

\subsection{Transportation Investment in the Urban Transportation Planning Process}

While pricing policies are typically proposed with the goal of improving short-run network efficiency, studies on investment principles are generally concerned with long-run 
efficiency assuming a priori the pricing policy (Wohl and Hendrickson 1984). Previous research on the network design problem (NDP) seeks to find the optimal network that serves a certain travel demand, or the optimal network enhancement given a budget constraint (Boyce et al. 1974, LeBlanc 1975, Poorzahedy and Turnquist 1982, Yang and Bell 1998, Meng et al. 2001). However, these studies, focusing on investment only, do not address the conflict between longrun economic efficiency and financial feasibility in reality.

Benefit-cost analysis has been extensively used in practice for strategic planning. Decision-makers have also developed practical investment rules dealing with problems of concern, most notably congestion, such as bottleneck removal and bottleneck bypassing (Zhang and Levinson 2005). Based on interviews of state and local transportation investment authorities, recent studies in Minneapolis-St. Paul (de Orca and Levinson 2006), and the D.C.-Baltimore area (Zhang and Yusufzyanova 2008) found that most agencies now give priority to systems preservation needs in the transportation investment process. The remaining revenue is then used for capacity programs and expansion. The major investment criteria in the allocation of capacity expansion funds include congestion mitigation, safety enhancement, and support for new economic development. These criteria can be either quantitative (e.g., volume-to-capacity ratios, future traffic volumes, level of service) or qualitative (e.g., a general objective for congestion reduction which provides more decision flexibility).

While the focus of this study is on freeway investment, the travel demand and travel time components of the model need to be specified. The monetary costs of infrastructure provision, user operating costs, and social costs on highways as a function of flow have recently been estimated (Levinson and Karamalaputi 2003), and these costs will be considered by the links in 
profit maximizing and the prices they charge. These need to be integrated and solved in both traffic equilibrium (Sheffi 1985) and long-term supply-demand equilibrium.

\subsection{Transportation Pricing and Joint Pricing-Investment Analysis}

Transportation economists have long been investigating various road pricing policies for the optimal allocation of scarce road resources, primarily from a theoretical framework (Dupuit 1844, Pigou 1920, Knight 1924, Mohring and Harwitz 1962, Vickery 1963, Walters 1968, Small 1992, Arnott et al. 1993, Button and Verhoef 1998, Gomez-Ibanez 1999, de Palma and Lindsey 2002, Verhoef 2002). Research in this field has advanced from first-best to various second-best pricing schemes, from time-independent to time-varying tolls, from assumptions of homogeneous users to heterogeneous users, and from assumptions of a single system operator to various ownership regimes. The majority of previous literature on road pricing (second-based congestion pricing, in particular) is based on a small parallel network; few studies examine price competition on a serial network (Levinson 1999, 2000, De Borger et al. 2006).

The economic theory also suggests that the optimal level of road investment is to expand a road to the point that the cost of one additional unit of capacity just equals the benefits it brings. An important finding, due to Mohring and Harwitz (1962), states that the revenue generated from the optimal pricing scheme is just sufficient to finance the optimal level of capacity under certain conditions. A series of studies have examined the validity of this "selffinancing rule," which is summarized by Verhoef and Rouwendal (2004). However, the theoretical analyses are typically performed under a strict set of economic conditions which, in some cases, hardly correspond to reality. Some have concerns that the revenue collected from short-run, marginal-cost pricing schemes may either exceed or fall short of the long-run facility 
supply cost due to (dis)economies of scale and/or non-optimality of existing road capacity. (Walters 1968, Gwilliam 1997). While the majority of road pricing literature considers a network of parallel roads, several studies examine revenue choices on a serial network managed by multiple jurisdictions (Levinson 1999, 2000).

Few studies consider price competition and capacity choices together. Keeler and Small (1977) develop a theoretical model to examine optimal peak-load pricing and investment on urban expressways. Verhoef and Rouwendal (2004) recently revisited this topic with additional considerations of second-best pricing policies. Zhang and Levinson (2006) consider pricing, investment and ownership dynamics simultaneously. Although the benefits of jointly considering price and capacity competition are obvious as they clearly influence each other, these studies show that the associated modeling efforts also increase significantly.

Assuming away user heterogeneity and the possibility of product differentiation could cause underestimation of the benefit of road pricing, as shown by several previous studies (Arnott et al. 1992, de Palma 1992, Schmanske 1993, Small and Yan 2001, Verhoef and Small 2004). It has been shown that with heterogeneity (i.e., different values of time), a single toll is inferior to differentiated tolls on two parallel roads. Most studies consider a two-link parallel network with two classes of users, with the exception of Verhoef and Small (2004) whose analysis is based on a continuous value of time distribution and a three-link parallel-serial network.

The use of small, stylized networks for economic analysis of road pricing is popular, allowing researchers to focus on the welfare consequences of alternative policy scenarios. Verhoef (2002) develops an algorithm to identify toll points and second-best tolls on a general network. A network model that considers price competition, capacity choice, user heterogeneity, 
and is still applicable to large networks has obvious values in that it permits researchers to check the validity of previous conclusions on large networks, and to model the welfare and distributional effects of road pricing and investment policies in more realistic decision scenarios.

\subsection{Transportation Network Ownership Structures}

Aside from the large body of literature on road pricing and strategic investment, the third aspect of transportation financing deals with ownership structure. Discussions in this field focus on transportation commercialization and privatization. Gomez-Ibanez and Meyer (1993) have reviewed transportation privatization at an empirical level, though the cases of roadway privatization are few and not entirely successful. It is unlikely that even if roadways were privatized that their price structure would be left entirely to the private sector. Roth (1996) reviewed positive aspects of road commercialization and privatization, and proposed a framework for creating a market economy of roads. In many ways, roadways are natural monopolies, as their provision and use has a declining average cost (aside from congestion effects). The relative advantages and disadvantages of various ownership regimes may also depend on the type of regulation (Kahn 1988, Train 1991). Winston and Shirley (1998) developed a quantitative model to study the welfare effects of transportation privatization with emphasis on the transit system.

Previous studies on road ownership have been experiential, and based conclusions on consequences of privatization in other economics sectors (Ross 1996) or on empirical observations of demand and cost characteristics of existing private roads (Gomez-Ibanez and Meyer 1993). Winston and Shirley (1998) were able to quantify the welfare loss in urban transit systems due to inefficiencies inherent to public ownership, but did not provide a model for 
analyzing road ownership. The empirical evidence, existing situations and political environment in many areas of the world suggest that the research question to answer is not, "Should all roads be privatized?" but "When, where and how can the concept of private roads help solve urgent transportation problems?" This requires quantitative, valid and flexible models of road ownership applicable in real-world networks. Such models would inevitably require the joint consideration of pricing and investment decisions by various types of road owners as well as their interactions on large networks and over a period of time. Several studies have examined the pricing dynamics between private toll roads and competing free-access roads (Verhoef et al. 1996, de Palma and Lindsey 2000, de Palma 1992, Viton 1995). de Palma and Leruth (1989) and Yang et al. (2002) considered price and capacity competition in congested networks. Levinson (2000) examined price competition between serial monopolists with revenue strategies. Recently, Verhoef and Rouwendal (2004) explored interrelations between pricing, capacity choice and financing in transportation networks using a small network model. Zhang and Levinson (2007) developed a mathematical model of transportation network evolution, and used the model to study pricing dynamics, capacity growth and welfare impacts under various ownership structures on several stylized, small networks. Their results suggest that the competition and complementarity among links in a road network significantly affect the pricing and investment decisions as well as the optimal network ownership structure. Profit-maximizing price and capacity are systematically biased from the socially optimal values. Public-private mixture appears to be a robust ownership arrangement in networks with various layouts. However, there is one drawback associated with the previous attempts to solve for the combined optimal pricing and investment choices analytically - the equation system or optimization program in these studies cannot be solved efficiently on large networks. 
Most previous economic studies consider the aforementioned three policy aspects (pricing, investment and ownership) of transportation network evolution separately, with a few exceptions. Keeler and Small (1977) developed a theoretical model to examine optimal peakload pricing and investment on urban expressways. Verhoef and Rouwendal (2004) recently revisited this topic with additional considerations of second-best pricing policies. Several studies consider alternative ownership regimes and toll choices on a small network with one OD pair and two or more alternative routes (DeVany and Saving 1980, de Palma 1992, Viton 1995, Verhoef et al. 1996, de Palma and Lindsey 2000). It appears that no previous study has considered pricing, investment and ownership issues jointly on hypothetical or real-world networks.

\subsection{General Modeling Methods for Transportation Economic Analysis}

There are different methodological tools which could be used to model transportation network dynamics. Following the seminal work by Pigou (1920) and Knight (1924), most economic studies on road pricing and financing adopt a theoretical framework and base the analysis on small hypothetical networks, which may be labeled as small network (equilibrium) models. Models of the transportation network as a physical system have been well developed in the transportation literature (Sheffi 1985). When there are multiple agents making pricing and investment decisions (e.g., private roads competing with public roads), an economic network arises which considers coordination and competition between decision-makers. Johansson et al. (1994) describe various economic networks from an empirical viewpoint, while Nagurney (1993) provides a computational framework, which links analysis of economic networks (suppliercustomer relationships) with algorithms developed for the analysis of physical networks. 
Economides (1996) compares the economic structure of networks with vertically related industries. Economic systems with multiple decision-making agents may not contain a neat equilibrium solution. Game theory (Von Neumann and Morgenstern 1944, de Palma 1992) provides an alternative means for capturing the interactions between agents in deciding prices and investments. A modeling approach using cellular automata (Langton 1989) suggests specifying simple rules and allowing the system to evolve. The transportation system is, in Sussman's (2000) words, a complex, large, integrated and open system. Modeling tools developed for analyzing complex systems, such as agent-based techniques (von Neumann 1966, Zhang and Levinson 2004), may also be used to model pricing, capacity and ownership dynamics.

The representations of travel demand pattern and cost structure on transportation networks are fundamental to transportation economic analysis. Transportation system users make a number of spatial and temporal choices that affect travel demand: residential and job locations, vehicle ownership, activity location and participation, timing, duration, trip chaining, travel mode, and routes. Traditionally, these choices are modeled in a sequential manner with trips as the basic analysis units, while integrated models have also received significant research interest (Boyce 2002). New activity-based approaches have emerged since a major breakthrough in behavioral geography in the 1970s (Hagerstrand 1970), and have been applied to aid transportation planning (Pas 1985, Kitamura 1988, Jones 1990, Axhausen and Gärling 1992). In transportation economics studies, the problem of road pricing traditionally has been set up for simplicity, with route choice and origin-destination travel frequency choice being the only two demand dimensions. Recently, several studies also consider departure time choice, employing Vichrey's (1969) bottleneck model (Bernstein and Muller 1993, Braid 1996, Liu and McDonald 
1999, de Palma and Lindsey 2000). Verhoef and Rouwendal (2004) developed an analytical model with vehicle ownership as one of the endogenous variables.

The cost of supplying road capacity usually involves land acquisition, construction and maintenance costs (Keeler and Small 1977, Zhang and Levinson 2005). Empirical studies of highway construction costs focus on the issue of whether the actual cost function exhibits constant returns to scale for its theoretical importance (Keeler and Small 1977, Krause 1981, Small et al. 1989, Levinson and Gillen 1998, Small 1999, Levinson and Yerra 2002). Recently, Levinson and Karamalaputi (2003) have estimated the construction cost function based on project-level data in the Twin Cities.

\subsection{Transportation and Land Use Growth Models}

A transportation network is a complex system that exhibits the properties of selforganization and emergence. Previous research in dynamics related to transportation networks focuses on traffic assignment or traffic management. However, the dynamics of transportation network growth have not been adequately studied. If a transportation network is represented by a directed graph, there are several important questions yet to be answered: (1) How do the existing links (roads) develop and degenerate?; (2) How are new links added to the existing network?; (3) How are new nodes added to the existing network?; (4) Do networks self-organize into hierarchical patterns?; and (5) Are roads (routes) an emergent property of networks?

One of the few previous studies (Yerra and Levinson 2002) in this area shows that even starting from a random or uniform pattern, a transportation network tends to self-organize into a hierarchical pattern in which some roads attract more traffic, receive proper maintenance and are

gradually expanded, while other roads are less popular, poorly maintained and may eventually be 
abandoned. It is also demonstrated that although this hierarchical pattern seems to be designed by planners and engineers, it is actually an intrinsic emergent property of networks themselves. The simulation model developed in that study assumes unlimited road capacity; the growth and decline of roads are reflected only by changes in their free-flow speeds. This presumption is relaxed in this study so that the impacts of network congestion on travel demand and supply can be incorporated in the analysis. Travel demand is represented by a more realistic user equilibrium pattern. In the network evolution process, links exhibit dynamics in both free-flow speed and capacity. The improved model is then applied to the Twin Cities transportation network with nearly 8,000 nodes and more than 20,000 links, which allows us to examine computational properties and predictive value of the proposed microscopic network dynamics model.

Few researchers have considered the process of transportation network growth at a microscopic level. Taaffe et al. (1963) study the economic, political and social forces behind infrastructure expansion in underdeveloped countries. Their study finds that initial roads are developed to connect regions of economic activity, and lateral roads are built around these initial roads. A positive feedback between infrastructure supply and population was also observed. Barker and Robbins (1975) investigated the London Underground's growth, but did not develop a theoretical framework as we are considering here. Miyao (1981) developed macroscopic models to take transportation improvements as either an endogenous effect of urban economy or as an exogenous effect on the economy. Endogenous growth theory suggests that economic growth is a two-way interaction between the economy and technology; technological research transforms the economy that finances it (Aghion and Howitt 1998). The technology of transportation is unlikely to be an exception, suggesting transportation investment drives the 
growth that funds it. Macroscopically, the growth of infrastructure follows a logistic curve and that road infrastructure also has reached saturation levels in developed countries (Grübler 1990). Miyagi (1998) proposes a Spatial Computable General Equilibrium (SCGE) model interacting with a transportation model to study the interaction of transportation and the economy. Yamins et al. (2003) developed a road growth model to study co-evolution of urban settlements and road systems from an empty space, with highly simplified travel demand and road supply mechanisms meaningful only for theoretical works. Garrison and Marble (1965) observed connections to the nearest large neighbor to explain the sequence of rail network growth in Ireland.

Carruthers and Ulfarsson (2001) find that various public service expenditures like roadways are influenced by demographic and political characteristics. The New Jersey Office of State Planning (1996) also finds a similar pattern in roadway expenditures. A related line of research examines how transportation investment affects the economy at large, but tends to treat transportation (or highways) as a black box and makes no distinction between different kinds of highway investment (Aschauer 1989, Button 1998, Gramlich 1994, Nadiri and Mamuneas 1996). Boarnet (1997), which considers county roads, is the most detailed of these types of studies. The input is investment in transportation (or infrastructure) and output is gross domestic product measured at the state or county level. While this research provides no assistance in actually making tactical management decisions, it suggests a way that a strategic macroscopic network investment budget can be established.

Geography's central place theory seeks to explain how hierarchies of places develop (Christaller 1966). Models developed by Batty and Longley (1985), Krugman (1996), and Waddell (2001) consider land use dynamics, allowing central places to emerge. However, those models take the network as a given. Clearly, there is a need for research that makes the network 
the object of study. In many respects, the hierarchy of roads is the network analogue of the central place theory.

A number of land use change models have been developed to forecast land use development while considering transportation as an important influencing factor. One of the first that gained substantive interest was the Lowry model (Lowry 1963). Several other model systems have adopted Lowry's methodology by examining basic, non-basic and service sectors sequentially, including DRAM, EMPAL, LUSDR and MetroScope models. Land use models such as POLIS and TOPAZ rely on mathematical programming methods. Multi-sector inputoutput analysis has also been applied to land use modeling by incorporating the spatial elements. Examples include MEPLAN and TRANUS. General equilibrium and computable general equilibrium land use models have also found applications (e.g., IUSMC and CSGE). More recently, advanced computing power has enabled the development of large-scale microsimulation land use models such as MASTER, UrbanSim, TILUMIP2 and Markovian land use change models. Since the 1980s, many integrated land use models have been applied in real cities and some have been developed into commercial packages. Examples include START (Bates et al. 1991), LILT (Mackett 1991), and URBANSIM (Waddell 2002). Timmermans (2003) provides a comprehensive review of these land use models. In most of these models, the dynamics of urban space have been played out as the outcome of the location decisions made by residents and businesses, in which both accessibility to employment and accessibility to population play essential roles (Hansen, 1959; Guttenberg, 1960; Huff, 1963).

The evolution of urban space has also been examined by another stream of studies. The pioneering work by von Thünen (1910) presented a monocentric city surrounded by agricultural land, and predicted the rent and land use distribution for competing socio-economic groups. 
Christaller (1933) introduced central place theory and demonstrated that a hierarchy of central places will emerge on a homogenous plain to serve the surrounding market while minimizing transportation costs. Krugman (1996) explores the phenomenon of self-organization in urban space. He developed an edge city model to demonstrate how interdependent location decisions of businesses within a metropolitan area could lead to a polycentric pattern under the tension between centripetal and centrifugal forces.

Although the concept of accessibility connects transportation with land use development, the change of transportation networks has seldom been considered in previous land use models, and vice versa. A possible explanation is that these models are already complicated enough. They usually involve multiple modeling approaches, incorporate numerous constraints and assumptions, and are estimated from empirical data, unavoidably leading to a comprehensive modeling framework including a wide variety of components. In contrast to those complicated and all-encompassing models that do not provide an explicit perspective, this project models the integrated dynamics of land use and transportation in as simple a way as possible that captures salient properties, enabling us to display and analyze the emergent hierarchy and agglomeration patterns of space and network on a large scale. 


\section{THE “ABSOLUTE" MODEL SYSTEM}

\subsection{Transportation - Land Use Growth and the Role of Freeway Investment}

The foremost and probably also the most important constraint on future network growth is the existing network. In developed countries where transportation infrastructure has reached its saturated stage, it is rare to see new network growth from a tabula rasa. Even in an empty place without any previous development, natural barriers such as rivers and mountains still constrain future network growth. The current network connectivity determines whether two links complement (upstream or downstream) or compete with (parallel) each other for demand. The existing network may or may not be at an equilibrium. It may still take years for road supply to meet existing travel demand even if no exogenous changes (e.g., population and economic growth) occur. The important question is how various forces drive the existing network to evolve, more than how long it takes.

Based on the current network, land use arrangements and individual socio-economic status, people make travel decisions such as trip frequency, scheduling, destination, mode and route choice. These decisions transform into travel demand on the transportation network. This demand-generating process involves the existing network supply, congestion externalities, travel behavior, and link-level travel demand forecasting.

If a freeway section is expanded, travel increases on that link because of re-routing and re-scheduling and due to what is often called induced or latent demand, a finding confirmed at both the macroscopic level (states and counties) (Noland 1998, Strathman et al. 2000, Fulton et al. 2000) and at the microscopic level (individual links) (Parthasarathi et al. 2002). As travel costs for commuters are lowered, the number and length of trips increase. The expanded freeway 
section with increased travel demand can generate even more revenue, which may later result in further expansion on that section. Yet this loop, while positive, should have limits. The diminishing returns in the revenue structure and exponential increases of expansion costs will eventually stop this feedback loop.

Increasing the capacity of one freeway will also cause complementary (upstream and downstream) links to have greater demand, and competitors (parallel links) to have less demand (and be less likely to be improved). These network effects take time to propagate within transportation networks. This highlights the importance of considering the full ramification of network expansion on future infrastructure decisions. Previous changes in the network, economy, demography, and even travel behavior cause a new travel demand pattern and, hence, new link costs and revenues. Accordingly, a new set of supply decisions will be made, generating new network changes. This loop is repeated until a long-run equilibrium is achieved.

Land use changes in an urban area are driven by various forces and are influenced by land development, rent/land price, location, regional economic growth, existing spatial distribution of activities, transportation costs, freeway capacity investment, and other transportation investment. The network growth due to transportation investment often causes transportation cost changes between origin-destination pairs, which results in changes in accessibilities to various locations (e.g., jobs, houses, shopping). The ease or difficulty for residents to reach destinations and for businesses to reach suppliers/customers leads to location changes, and the relative desirableness of locations in the urban area. The land supply and land demand are equilibrated with a variety of price signals (e.g., land price, housing price, office/apartment rent). The re-allocated activities, in turn, imply a new travel demand pattern on the transportation network (the feedback to transportation). These aforementioned land use 
changes and transportation network changes often occur on dissimilar time scales, adding to the difficulty of modeling this co-evolution process.

\subsection{Overview of the ABSOLUTE Model System}

ABSOLUTE (Agent-Based Simulator of Land Use and Transportation Evolution) was developed for a previous OTREC project (Zhang et al. 2009). Since that project report may not be accessible to many readers of this report, the main modules and the mechanism of ABSOLUTE are also described in detail herein. A major improvement is the addition of an agent-based travel demand model, while the previous ABSOLUTE system only employs a traditional four-step demand model.

ABSOLUTE models the evolutionary process in the land use-transportation system described in Section 3.1. This evolutionary process is driven by the decisions of individuals, households, businesses, developers and regulators. These decisions are often made on different time scales. For instance, travel behavior regarding destination, departure time, model and route choice can change overnight. Pricing, taxation and infrastructure investment decisions take longer and are usually made annually or biannually. Location choices respond to transportation network capacity and cost changes in the long run, and may take decades to change. In the prototype model, it is assumed that all decisions are annual decisions and that each year the land use-transportation system achieves a short-run equilibrium wherein travel demand, transportation costs and location choices are equilibrated.

The main modules of ABSOLUTE are illustrated in Figure 3.1. As transportation network grows over time, a series of short-run equilibria will be observed until a long-run urban

growth equilibrium is reached. At the urban growth equilibrium, there is no incentive for a 
transportation user to unilaterally change travel behavior, for a transportation authority to unilaterally expand or denigrate the transportation network, and for households or firms to unilaterally change their land use decisions. In this co-evolution model, transportation network growth causes land use changes, which results in new travel demand patterns, produces new demand for infrastructure and, in turn, affects future network growth. Land use and the transportation network, therefore, co-evolve until the long-run urban growth equilibrium is achieved. This equilibrium concept reflects a central tendency and therefore is useful for land use and transportation policy evaluation, while in reality it may never be achieved due to continuous exogenous changes in regional population and economy.

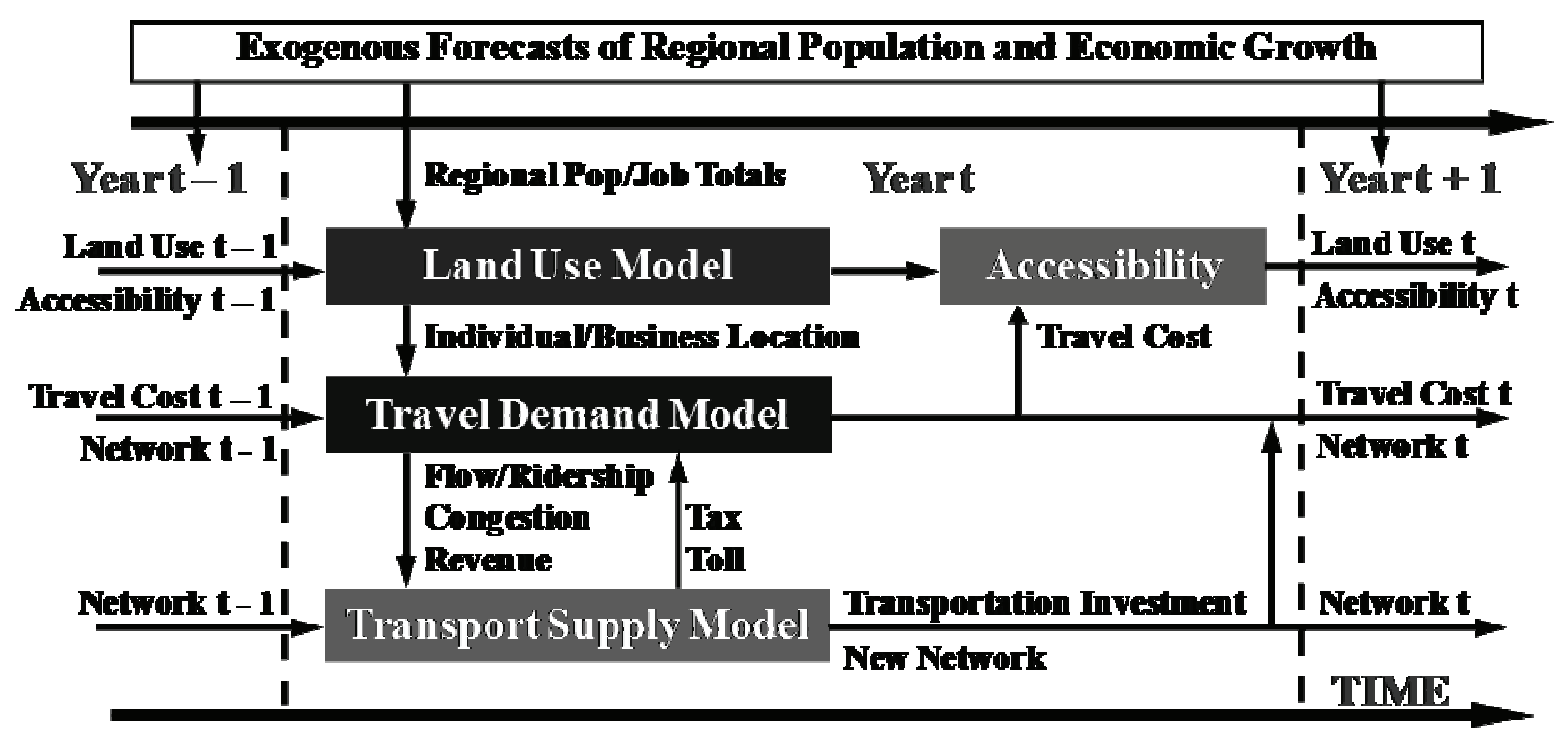

Figure 3.1. Flowchart of ABSOLUTE Model System

Section 3.3 presents the details of the land use model and the accessibility measures. The land use model takes exogenous population and economic growth, and allocates jobs and houses to individual zones in the urban system based on previous-year accessibility measures and land 
use. The relocation of land use activities, as well as new changes in transportation costs, leads to changes in accessibility measures. Two different travel demand models have been developed for this system: a traditional four-step model (described in Section 3.4) and an agent-based travel demand model (presented in Section 3.5). The demand model provides system usage (e.g., traffic flows on links) and congestion information to the supply model for the determination of revenue and new investment. The transportation supply model has a cost module, a pricing module and an investment module, which is presented in Chapter 4 due to its complexity. Section 3.6 discusses the calibration and validation of the ABSOLUTE model system.

The following notation convention is used in the discussion of individual ABSOLUTE modules:

$A_{r} \quad$ accessibility of zone $r$

$C S^{0-i}$ change in consumers' surplus from year 0 to $i$

$d($.$) \quad cost impedance function in the gravity model; d\left(t_{s s}^{i}\right)=e^{-\gamma \cdot t_{s}^{i}}$

$D_{s} \quad$ number of trips destined for zone $s$

$D R_{a}^{i} \quad$ disposable revenue of link $a$ in year $i$ (dollar)

$E_{a}{ }^{i} \quad$ revenue (earnings) of link $a$ in year $i$ (dollar)

$K_{a}^{i} \quad$ cost of expanding link $a$ in year $i$ (dollar)

$f_{a}^{i} \quad$ average hourly flow on link $a$ in year $i(\mathrm{veh} / \mathrm{hr})$

$F_{a}{ }^{i} \quad$ capacity of link $a$ in year $i(\mathrm{veh} / \mathrm{hr})$

$G \quad$ Gini coefficient of accessibility inequity

$i \quad$ index of year

$j, k \quad$ parameters in the decentralized pricing model 
$l_{a} \quad$ length of link $a$ (constant) $(\mathrm{km})$

$m_{r}, n_{s}$ coefficients in the gravity model

$M_{a}{ }^{i} \quad$ cost of maintaining link $a$ in year $i$ (dollar)

$O_{r} \quad$ number of trips produced from zone $r$

$q_{r s}{ }^{i} \quad$ demand from origin $r$ to destination $s$ in year $i$

$t_{a}^{i} \quad$ generalized travel cost on link a in year $i$

$t_{r s}{ }^{i} \quad$ generalized travel cost from zone $r$ to $s$

$v_{a}{ }^{i} \quad$ free-flow speed of link a $(\mathrm{km} / \mathrm{hr})$ in year i

$\alpha_{1-3} \quad$ coefficients indicating (dis)economies of scale

$\phi \quad$ scale parameter in expansion cost function

$\gamma \quad$ coefficient in the impedance function

$\lambda \quad$ value of travel time (dollar $/ \mathrm{hr})$

$\theta_{1-2} \quad$ coefficients of the BPR travel time function

$\rho_{l-2} \quad$ coefficients in the centralized pricing model

$\sigma_{l-3} \quad$ coefficients in the expansion cost model

$\tau_{a}^{i} \quad$ link toll per vehicle (dollar)

$\mu \quad$ scale parameter in maintenance cost function

$\omega_{1-2}$ coefficients in the capacity-speed model

$\psi \quad$ coefficient to scale hourly flow to annual flow

\subsection{Accessibility Measures and the Land Use Model}

Accessibility is the product of a temporal element reflecting travel costs (e.g., the impedance function from gravity models applied to the travel time between two zones) and a 
spatial element reflecting the distribution of the activities in a region (for instance, number of jobs or houses) (Burns 1979, Hanson 2004). It measures the available activities, such as job opportunities, that can be reached within a certain amount of commuting time, or the ease of reaching destinations. Accessibility is just one of the various factors that affect urban spatial patterns. Several previous studies conclude that accessibility has ambiguous influences on employment and residential distributions in a region (Adams 1999), while others suggest that accessibility changes significantly affect location choices (Payne-Maxie Consultants 1980). Nevertheless, the fact that urban regions do not extend infinitely over space indicates that commuting time and accessibility are significant factors. The fact that the actual commute exceeds the minimum required commute (however defined) indicates that accessibility is not the only factor.

We adopt two standard measures of job and residential accessibility to convert travel time changes into accessibility shifts. The impedance function is drawn from a previously estimated gravity model for work-trip distribution in the Twin Cities, MN.

$$
\begin{aligned}
& A_{i, E}=\sum_{j}\left[E_{j} f\left(t_{i j}\right)\right] \\
& A_{i, P}=\sum_{j}\left[P_{j} f\left(t_{i j}\right)\right] \\
& f\left(t_{i j}\right)=\exp \left(a+b t_{i j}\right)=\exp \left(-0.97-0.08 t_{i j}\right)
\end{aligned}
$$

Where:

$A_{i, E}: \quad$ Accessibility to jobs (employment) from zone $i$

$A_{i, P}: \quad$ Accessibility to houses (residence) from zone $i$

$E_{j}: \quad$ Number of jobs (employment) in zone $j$

$P_{j}$ : $\quad$ Number of houses (residence) in zone $j$ 
$f\left(t_{i j}\right): \quad$ Impedance function of travel time between zones $i$ and $j$

$t_{i j}: \quad$ Peak-hour auto travel time from zones $i$ to zone $j$

With a number of zonal opportunities such as jobs and houses in the definition, these two accessibility measures determine the likelihood that a job (or house) would be filled by a person according to how easy the person can reach it. Similar accessibility measures were used in many previous studies (Handy 1993, Hanson 1987, Levinson 1998, Williams 1989, among others).

The land use model used is a land use change indicator model. The original land use change indicator model (LUCI) assumes the availability of the base-year population and employment data (Roberts and Simmonds 1997). Another model input is the accessibility in the transportation network in both the base year and the forecast year. The LUCI model is a simplified version (without market segmentation) of the regional growth allocation models used by many Metropolitan Planning Organizations. The model has a logit functional form as follows:

Population (Housing) Redistribution:

$P_{i}^{2}=P \frac{P_{i}^{1} \exp \left[b\left(A_{i, E}^{2}-A_{i, E}^{1}\right)\right)}{\sum_{i} P_{i}^{1} \exp \left[b\left(A_{i, E}^{2}-A_{i, E}^{1}\right)\right)}$

$P: \quad$ The fixed total study area population

$P_{i}^{2}$ : New zonal population resulting from an accessibility change

$P_{i}{ }^{l}: \quad$ The initial population of zone $i$

$b$ : The calibrated sensitivity coefficient in the accessibility measure

$A^{2}{ }_{i, E}: \quad$ The new accessibility to work of zone $i$

$A^{1}{ }_{i, E}$ : The initial accessibility to work of zone $i$ 
Employment Redistribution:

$$
E_{i}^{2}=E \frac{E_{i}^{1} \exp \left(A_{i, P}^{2} / A_{i, P}^{1}\right)^{b}}{\sum_{i} E_{i}^{1} \exp \left(A_{i, P}^{2} / A_{i, P}^{1}\right)^{b}}
$$

E: $\quad$ The fixed total study area employment

$E_{i}^{2}$ : New zonal employment resulting from an accessibility change

$E_{i}{ }^{l}: \quad$ The initial employment of zone $i$

$A_{i, P}^{2}$ : The new accessibility to house of zone $i$

$A_{i, P}^{1}$ : The initial accessibility to house of zone $i$

LUCI is an empirical spatial interaction model. An interpretation of the model is that due to changing travel costs between origins and destinations, jobs and houses located in a specific zone may become more (or less) accessible relative to other zones in the region, which leads to increased (or decreased) level of future jobs and houses in that zone. The total regional employment and housing units are kept constant. Therefore, LUCI is strictly a land use redistribution model and not a growth model. The extent of the land use redistribution process depends on the calibrated coefficient $b$ in the travel time impedance function, which can be interpreted as users' willingness to travel further for better activity locations.

Accessibility in the original LUCI model is simply defined as a travel time decay function without considering activity opportunities at various destination zones. In order to adopt the more reasonable accessibility measures in Equations (3) and (4), the model structure needs to be modified. The modified model for residential redistribution is: 


$$
P_{i}^{2}=P \frac{P_{i}^{1} \exp \left[\frac{b}{\bar{E}}\left(A_{i, E}^{2}-A_{i, E}^{1}\right)\right]}{\sum_{i} P_{i}^{1} \exp \left[\frac{b}{\bar{E}}\left(A_{i, E}^{2}-A_{i, E}^{1}\right)\right]}
$$

$\bar{E}: \quad$ Average zonal employment of the study area

The sensibility of land use to accessibility changes is now $b / \bar{E}$ instead of $b$ in the original model. Since the employment model has a fractional form relating the accessibility in the base year to that in the forecast year, no modifications are required. Equations 5.1 5.6 constitute the modified land use change indicator model.

\subsection{Four-Step Travel Demand Model}

A traditional four-step model is specified to estimate travel demand at the link level, taking exogenous land use, socio-economic variables and the existing network as inputs. Although the four-step model serves well for demonstration purposes in this paper, future studies should use more advanced travel demand models. For instance, combined travel demand models address inconsistencies in the sequential model by solving all steps in a coherent equilibrium (Boyce 2002). Activity-based approaches (Kitamura 1988) and agent-based micro-simulation (Zhang and Levinson 2004) improve behavioral representation in travel demand models. A zone-based regression structure is used for trip generation. The origin-destination (OD) cost table obtained from the previous-year traffic assignment is used for trip distribution in the current year based on a doubly constrained gravity model.

$$
q_{r s}^{i}=m_{r} O_{r} n_{s} D_{s} \cdot d\left(t_{r s}^{i}\right)
$$


The resulting OD table is loaded onto the current-year transportation network through the origin-based user equilibrium traffic assignment algorithm (OBA) (Bar-Gera and Boyce 2003). The generalized link cost function comprises two parts, a BPR travel time component and a vehicle toll.

$$
t_{a}^{i}=\lambda \frac{l_{a}}{v_{a}^{i}}\left[1+\theta_{1}\left(f_{a}^{i} / F_{a}^{i}\right)^{\theta_{2}}\right]+\tau_{a}^{i}
$$

The OBA algorithm derives link flows at user equilibrium and generates a new OD cost table that will be used for trip distribution in the next year. This means in principal all of the demand could find new destinations each year though, in practice, once the system approaches equilibrium the year-to-year changes are small. In the traffic assignment step, if the relative excess travel cost is less than 0.001 , the Wardrop user equilibrium is considered to be satisfied.

\subsection{Agent-Based Travel Demand Model}

\subsubsection{Overview of the Agent-Based Demand Model}

A number of factors affect users' choices of trip frequency, destinations and routes. Traditionally in road pricing studies, trip frequency choices, and to some extent destination choices, are represented by a downward-sloping demand curve for each OD pair, which is assumed known a priori. Route choices are often modeled using the user equilibrium traffic assignment principle. On a large complex network, this approach may become problematic as there are substitutional effects between destinations and the actual OD demand curves are interdependent. The traditional user equilibrium assignment principle was originally proposed for a single class of homogeneous users. While the concept of "generalized cost" allows the 
consideration of toll and travel time in assignment, it does not provide an algorithm to assign heterogeneous users with distinct values of time on general networks. Recent advancement in the bi-criterion user equilibrium principle is promising, but requires further development. In order to consider heterogeneous users on complex networks, the travel demand model in this paper adopts a novel agent-based approach, simulating travel choices for each individual user. Zhang and Levinson (2004) developed an agent-based destination and route choice model, and calibrated the model for the Chicago road network. However, their model assumes that travel time is the only choice factor and that all users are identical. These assumptions are removed in the following improved model. The term "agent-based" implies that agents in this model have individual behavioral rules, possess learning capabilities, interact with other agents, and adjust their behavior adaptively over time.

It is assumed that the residential locations of all users are known, and that all tolls are set by respective road authorities. The agent-based demand model then simulates the trip frequency (i.e., trip or no trip), destination and route choices. The following subsections present the model details.

\subsubsection{Agents}

Traveler

There are three types of agents in this agent-based travel demand model: traveler, node and arc. Each "traveler" agent simply corresponds to a road user in the real world. A traveler is characterized by residential location, travel budget $(u)$, value of time $(v)$, and perception threshold $(T)$. The number of travelers residing at each residential location is limited by the available houses at the location. Travel budget determines how far a traveler is willing to travel 
for a specific activity, an important factor in destination choice. Value of time provides travelers the impetus to choose routes with different travel times and toll combinations. Perception threshold reflects the inertia for people to change routes, measured by savings in generalized route costs. Currently in the model, all four traveler attributes are drawn from pre-determined distributions and remain unchanged for each traveler throughout the agent-based simulation period.

One of the two goals for each traveler is to find an activity opportunity that is located just far enough from the residential location such that the travel budget is exhausted. The evidence that travelers maintain commuting travel times, daily overall travel times, and generalized commuting costs is supported by research in the travel behavior literature, although by no means has this been resolved conclusively (See Mokhtarian, 2004, for a review of the literature). As time is not fungible in the same way as money, there are separate time and money budgets. Travelers may have a threshold beyond which they won't travel.

The second goal is to identify the route to the chosen destination with the lowest generalized cost given the traveler's value of time. Travelers attempt to achieve this goal through both accumulating personal experience during random exploration of the road network and learning from other travelers. However, travelers may not achieve their destination and/or route choice goals in the model, as they do not have perfect information or perfect decision rules. This will be explained later in the subsection on behavioral rules.

Node

In order to maintain a parsimonious model structure, each "node" agent represents three identities in the real world: (1) A vertice of the physical road network where roads (arcs) are connected; (2) A centroid of the study area where residents and activity opportunities are located 
(Note: The number of residents and available activity opportunities at an individual node are assumed constant and determined by exogenous land use data in the current model); (3) A place where travelers can exchange information and learn from each other. The third representation deserves some further explanations. In reality, travelers learn destinations and routes from other travelers in many different ways. For instance, such information exchange can occur in offices, neighborhood parks, restaurants, shopping centers, or through phone conversations and emails. For simplicity, it is assumed that all information exchanges take place at nodes.

Since nodes are now places for information exchange, and collectively travelers retain knowledge about the shortest paths between places in the network, it is assumed that each node stores the information of $K_{1}$ shortest travel-time path and $K_{2}$ lowest toll path from every other node to itself. This is necessary for users with high and low values of time to find their personal best paths. As a traveler departs, visits or arrives at a node, the traveler and the node exchange information regarding shortest paths, which replicates actual, real-world learning behaviors among travelers. After each occurrence of traveler-node information exchange, travelers can provide the updated information to nodes they visit later. Similarly, the node can transfer the updated shortest-path information to subsequent visiting travelers.

This distributed learning mechanism does not guarantee the identification of the true shortest paths. However, it does realistically reflect travelers' limitations with regard to learning and information acquisition. Simulation results show that travelers are more likely to find the true shortest paths if the network is smaller (fewer alternative routes) and if the total number of travelers in the network is larger (more learning opportunities). In Zhang and Levinson (2004), an earlier version of this learning rule that does not take into consideration congestion effects or user heterogeneity demonstrates that travelers can identify more than $99 \%$ of shortest paths on 
the Chicago network of all major roads. For readers who are interested in more details of this route-learning algorithm, an illustrative example is provided in Appendix A.

Arc

An "arc" agent corresponds to a physical directional road on the network. Each arc is labeled with its origin node, destination node, capacity $(F)$, free-flow travel time $\left(t_{0}\right)$, toll rate $(\tau)$, and ownership $(O)$. Congested link travel time $(t)$ and generalized link cost $(c)$ can be derived from a standard link flow-cost function. The standard BPR link performance function is currently employed in the model with coefficients 0.15 and 4. Each road also makes pricing and capacity investment decisions in response to demand elasticities and its welfare- or revenue-maximizing goals, which is beyond the scope of the travel demand model and belongs within the next section on price and capacity choices.

\subsubsection{Behavioral Rules and Interactions}

This subsection describes how aggregate demand patterns can be derived from the behaviors of and interactions among the three types of agents.

Given an initial residential location, each traveler examines activity opportunities by randomly exploring surrounding nodes starting from the origin. The probability of moving to a specific node in the next step is proportional to the amount of remaining activity opportunities

located at that node. During this initial random exploration process, travelers accumulate their initial network knowledge that can be used for information exchange in later iterations. The randomness of searching direction and a large number of travelers ensures a diversity of initial route choices, which comprise the initial route choice set for subsequent iterations. In addition, 
travelers in the model do not visit the same node twice, and all circular routes in a destination search are eliminated. This ensures that travelers will also consider nodes further away from their origins, thought they are more likely to visit nearby nodes. A traveler selects a destination node once a personal travel budget is reached, or decides not to travel at all if no destination node previously visited satisfies the travel budget because all activity opportunities have been taken by other travelers. This initial destination choice algorithm can be viewed as a stochastic microscopic implementation of the intervening opportunities model (Stoufer 1940, Haynes and Fotheringham 1984) with a travel budget.

Once a traveler arrives at the destination that satisfies the travel budget, this destination and the corresponding route choice after the initial round of information exchange would be the travelers' final destination and route choice if there was no congestion in the network. However, on congested networks travelers often need to adjust their destination and/or route choices iteratively in response to other travelers' choices.

In each subsequent adjustment iteration, a traveler first follows the route chosen at the end of the previous iteration. When visiting each node on this route, the traveler exchanges information (about travel time and tolls) with the node, and thereby spreads this information along the route for other travelers who may have different values of time. When a traveler learns a new route from nodes, the traveler must determine whether or not to switch to the new route. The alternative paths are evaluated in dollar values by considering the individual value of time and toll charged by each link segment. A route-switching rule is then followed. 


$$
\begin{cases}p=\frac{e^{-\frac{s}{b} \gamma-T}}{e^{-\frac{s}{b} \gamma-T}+e^{-0.5 \gamma^{*} T}} & \text { if } \mathrm{b}>\mathrm{T} \\ p=0 \quad \text { otherwise }\end{cases}
$$

Where

$p$ : $\quad$ Probability of switching to the new route

$b: \quad$ Actual benefit of switching route measured in dollars

T: $\quad$ Perception threshold of the traveler measure in dollars

$\gamma$ and $s:$ Parameters defining the shape of the probability curve. A larger $\gamma$ implies the probability drops faster when the benefit reduces.

When travelers switch routes, arc flows and travel times are updated according to the arc link performance function. Consequently, the cost of all paths stored at nodes and learned by travelers would also change, which may trigger further route switching. A route choice equilibrium is achieved if no traveler, given the information available and value of time, has incentives to change routes. This is similar to the Behavioral User Equilibrium concept in Zhang (2006). However this model differs from Zhang (2006) in its implementation of route search and choice rules.

As the level of congestion and toll evolves in the network, some travelers may find that none of the learned routes from their origins to the selected destinations satisfies their travel budgets. Destination choice adjustments are necessary in addition to route choice adjustments. The implicit assumption is that travelers first attempt to change routes to satisfy their travel budgets when costs increase due to tolling and/or congestion. When destination changes are 
necessary, travelers will investigate the nodes adjacent to their current destinations in order to reduce their travel costs and eventually satisfy their travel budgets. The travel cost to any one of the adjacent nodes is the shortest path from the travelers' origin evaluated according to their individual values of time. It is possible in any destination adjustment iteration that more travelers ( $D_{d}$ : destination demand) may wish to select a specific node as their destinations than what the node can accommodate ( $D_{s}$ : destination supply which is the total number of activity opportunities). In that case, each traveler has a probability of $D_{s} / D_{d}$ of changing destination to the new node. Those travelers who could not change destination to the new node will continue to search other adjacent nodes. A traveler may need to change their destination more than once to satisfy their travel budget. When all travelers either are satisfied with their destinations or cancel their trips because a satisfactory destination cannot be found, a destination choice equilibrium is achieved.

The combined route-destination choice equilibrium of the agent-based travel demand model can be reached by simulating the route choice equilibrium and destination choice equilibrium in an iterative fashion. A new route choice equilibrium implies new travel costs between origins and destinations, causing additional destination adjustments. A new destination choice equilibrium provides a new origin-destination demand pattern for the further route choice adjustments. The combined route-destination choice equilibrium is achieved when the maximum origin-destination demand difference (or maximum link flow difference) between consecutive destination (route) choice equilibria is smaller than a pre-defined threshold value. 


\subsection{Discussion on Model Calibration and Validation}

The ABSOLUTE model should be calibrated and validated against observed time-series network and land use data. The calibration procedure may consist of two stages. The parameters in the sub-models (demand, revenue, cost and investment) are estimated from empirical network data. These estimates then form a starting solution for an iterative optimization routine with an improving search algorithm. Finer adjustments to the model system and parameters should be undertaken based on an objective function, which can minimize the difference between the observed data and the model ability to predict which links were improved and by how much. In brief, the model parameters form a space which can be searched systematically to find a best fit between actual and predicted link expansions and contractions. For instance, the transportation network data in the Twin Cities metro area have been collected between 1978 and the present in digital format, while data collection work on corresponding land use and economic information is ongoing. In the most recent (2000) Twin Cities transportation planning network, there are 7,976 nodes and 20,914 links. A bit more than 600 link expansions have taken place since 1978, which implies the Twin Cites transportation network is mature.

Although a rigorous calibration and validation of all coefficients in the transportation network growth and land use change models are beyond the scope of this exploratory research project, simulating the co-evolution model in contrived or real-world urban systems can still provide valuable information regarding the modeling concept, structure and feasibility for realworld applications. The values of the model parameters are currently determined from either empirical estimation using the Twin Cities dataset (network growth data from 1978-1998 and the existing four-step travel demand model), or our best understanding of the economies and 
diseconomies of scale in the network growth process. These preliminary model coefficient estimates are summarized in Table 3.1.

Table 3.1. Coefficients in the ABSOLUTE Model

\begin{tabular}{|c|c|c|c|}
\hline Parameter & Description & Value & Source \\
\hline$\lambda$ & value of travel time constant $(\$ / \mathrm{hr})$ & 10 & Empirical findings \\
\hline$\theta_{1}, \theta_{2}$ & coefficients in the BPR function & $0.15,4$ & BPR \\
\hline$\gamma$ & coefficient in the gravity model & 0.1 & Empirical findings \\
\hline$\rho_{l} \cdot \psi$ & $\begin{array}{l}\text { Combined scale coefficient in revenue } \\
\text { model }\left(\text { dollar } \cdot \mathrm{hr}^{\rho 3} / \mathrm{km}^{\rho 2+\rho 3}\right)\end{array}$ & 1 & Scale parameter \\
\hline$\rho_{2}$ & Power term of length in revenue model & 1 & CRS of link length \\
\hline$\rho_{3}$ & Power term of speed in revenue model & 0.75 & DRS of level of service \\
\hline$\mu$ & $\begin{array}{l}\text { Scale coefficient in cost model } \\
\left(\text { dollar } \cdot \mathrm{hr}^{\alpha 2} / \mathrm{km}^{\alpha 1}\right)\end{array}$ & 20 & Scale parameter \\
\hline$\alpha_{1}$ & Power term of length in cost model & 1 & CRS of link length \\
\hline$\alpha_{2}$ & Power term of capacity in cost model & 1.25 & IRS of capacity \\
\hline$\omega_{1}, \omega_{2}$ & $\begin{array}{l}\text { coefficient in the speed-capacity log- } \\
\text { linear regression model }\end{array}$ & $-30.6,9.8$ & $\begin{array}{l}\text { Empirical estimate based } \\
\text { on Twin Cities data }\end{array}$ \\
\hline$\beta$ & capacity change coefficient & 0.75 & DRS in link expansion \\
\hline$b$ & $\begin{array}{l}\text { Accessibility measure and land use } \\
\text { change coefficient }\end{array}$ & -0.08 & Empirical findings \\
\hline
\end{tabular}

CRS, DRS and IRS: constant, decreasing, and increasing returns to scale 
Since the agent-based travel demand model is a new module developed in this project, its calibration is conducted and presented below. We derived a set of model parameters for the standard Sioux Falls test network, which contains 24 nodes, 76 links and 33,640 peak-hour trips as seen in the previous traffic-assignment literature (see Figure 3.2, e.g. LeBlanc 1975). The distribution of the travel budget determines how long travelers are willing to travel, which is calibrated against received trip length data (which comes from a standard data set used for testing of assignment algorithms). We found that a log-normal distribution of travel budget with a mean of 35.4 min and a standard deviation of 13.4 minutes provide the best fit (see Figure 3.3).

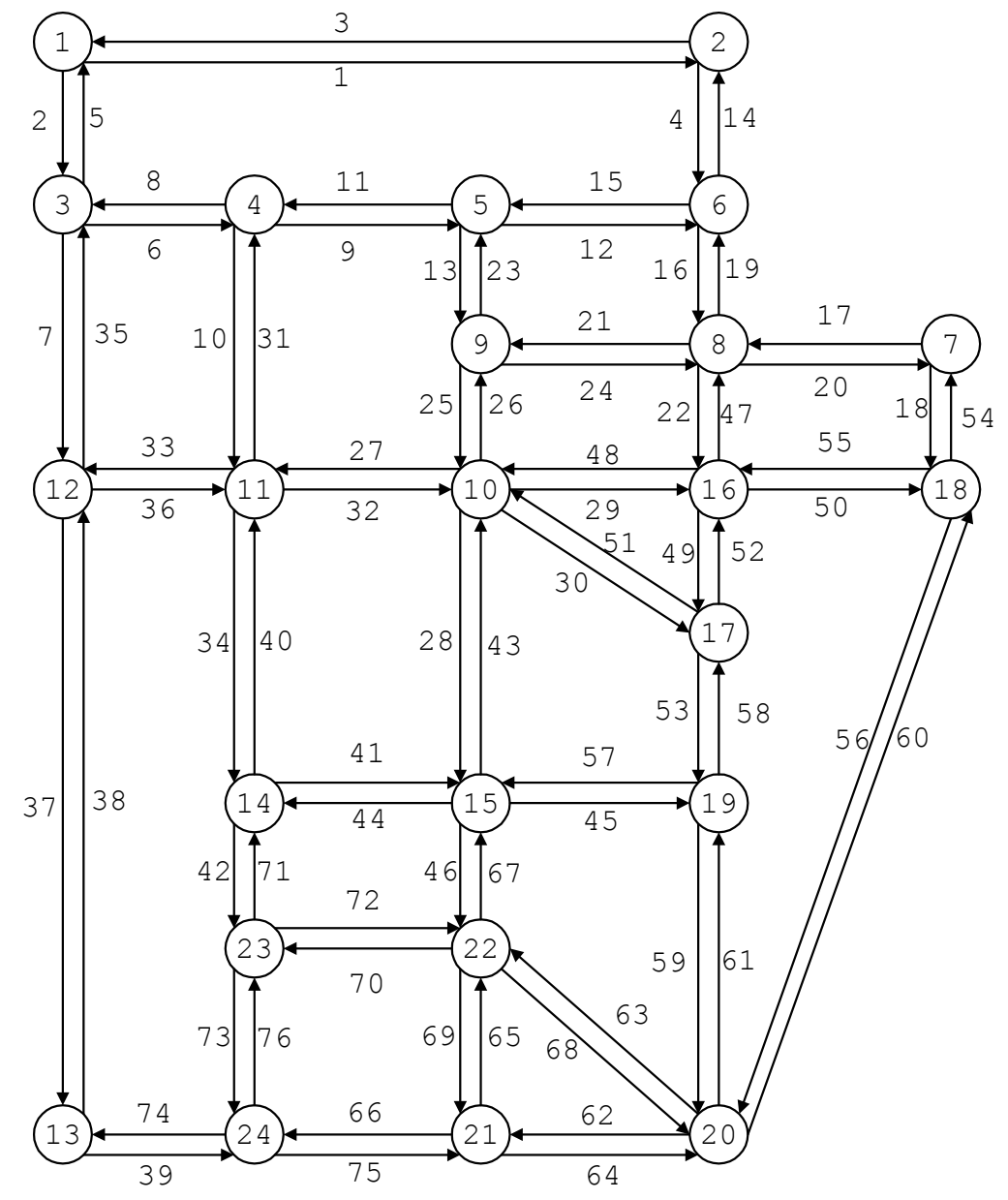

Figure 3.2. The Sioux-Falls Network (Numbers are Node and Arc Indices) 


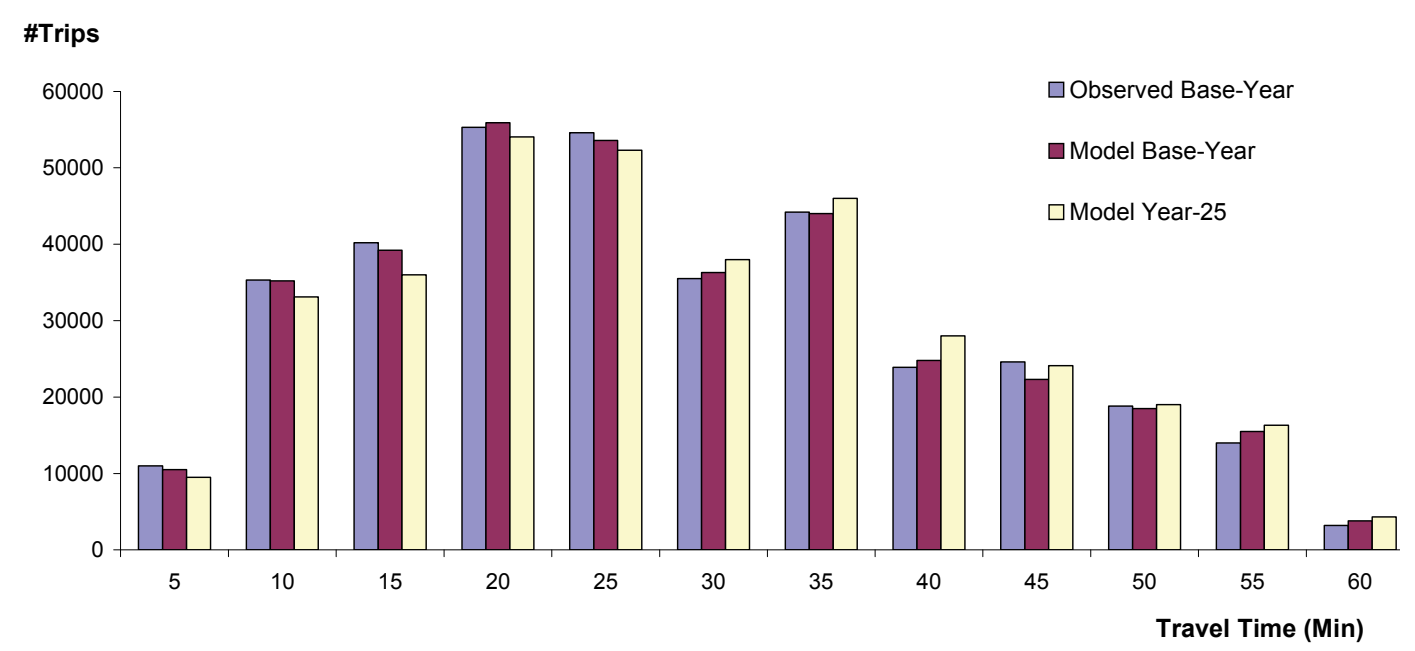

Figure 3.3: Received and Modeled Travel Time Distributions on the Sioux-Falls Network

Value of time is another important characteristic of travelers and may be derived from stated preference survey data. However, such a survey is not available for the Sioux Falls area. We assume that users' values of time follow a log-normal distribution (non-negative and leftskewed as the observed income distribution) with both the mean and standard deviation being $\$ 15 /$ hour. It should be noted that there is evidence of intra-personal variations of value of time, which implies an imperfect correlation between income and value of time. In the simulation tests, alternative distributions of values of time will be examined.

Coefficients in the route switching rule and travelers' perception thresholds decide the route choice equilibrium in the agent-based model. Since the Sioux Falls network is a relatively simple network, travelers should be able to identify shortest paths even when the network is congested. We therefore calibrate the route choice coefficients against a standard user equilibrium traffic pattern by enforcing uniform values of time for all travelers in the agent-based 
model. The final calibrated coefficients are $\gamma=1, T=\$ 0.10$, and $s=2$ ), which both ensure fast convergence for the agent-based model, and provide flow results consistent with user equilibrium assignments. The mean (maximum) link flow difference between the agent-based model and user equilibrium is $2.4 \%(6.4 \%)$ under this set of route choice coefficients. On larger networks, the route choice coefficients should be calibrated against observed route choices. 


\section{MODELING TRANSPORTATION PRICING AND INVESTMENT POLICIES}

The land use and travel demand modules described in Chapter 3 capture the collective consequences of travelers' and businesses' locational and travel behavior, and predict traffic flows on individual links based on the network from the previous year and exogenous socioeconomic and demographic information. On the policy side, a pricing strategy determines tolls and/or taxes, which both influence travel demand and generate a stream of revenue. Road owners, public or private, also adopt an investment policy to use this revenue based on their objectives and priorities. The revenue can be used to defray road maintenance costs, and/or to build new capacity, and/or to invest in other sectors of the economy. In order to achieve investment objectives, the cost structure (i.e., facility construction and maintenance costs) of the system must also be known. After a set of investment decisions are made based on revenue and cost estimates, freeways and other roads in the transportation network may grow with expanded capacity or degenerate (when not appropriately maintained), which is the supply-side change in the transportation system. A "No-More-Freeway" requirement would become a constraint in the models of pricing and investment policies.

This chapter is organized as follows: Section 4.1 describes the cost functions for the estimation of capacity expansion and road maintenance activities. The presentation of our models of pricing and investment policies are divided into four sections based on the assumed ownership structure: all public-sector ownership (Section 4.2); all public-sector ownership with a "No-More-Freeway" constraint (Section 4.3); all private-sector ownership (Section 4.4); and mixed public-private ownership (Section 4.5). In order to establish a benchmark to compare 
alternative investment policies, including the "No-More-Freeway" policy, the socially optimal pricing and investment decisions are also modeled in Section 4.6. For consistency, the same notation convention in Section 3.2 is followed in this chapter.

\subsection{Cost Functions}

Road construction and maintenance costs are modeled separately. The specification of the construction cost function is based on recent empirical findings in Levinson and Karamalaputi (2003), who estimated a Cobb-Douglas cost function based on more than 100 recent highway construction projects in the Twin Cities. Their findings suggest that the cost structure exhibits increasing returns to scale with respect to lane miles of construction, and it is more expansive to construct higher level roads (often with higher levels of existing capacity). The following specification captures these effects by incorporating kilometers of roadway construction $(l)$,

additional capacity added $\left(F^{t+1}-F^{t}\right)$, existing road capacity $\left(F^{t}\right)$, and a technology factor (ø), where $t$ is the index of time.

$$
K_{a}^{t}=\phi \cdot\left(l_{a}\right)^{\sigma_{1}} \cdot\left(F_{a}^{t}\right)^{\sigma_{2}} \cdot\left(F_{a}^{t+1}-F_{a}^{t}\right)^{\sigma_{3}}
$$

Few academic studies have empirically estimated the maintenance cost of individual facilities. We assume that it depends on the length and the capacity of the specific road. Furthermore, it is assumed that maintenance cost has constant returns to scale with respect to length, and decreasing returns to scale with respect to capacity (1.25). The technology factor $(\mu)$ is adjusted so that the total base-year maintenance cost matches the total 2005 preservation and maintenance costs estimated by the Minnesota DOT.

$M_{a}^{t}=\mu \cdot\left(l_{a}\right)^{\theta_{1}}\left(F_{a}^{t}\right)^{\theta_{2}}$ 


\subsection{Pricing and Investment Policies under Public-Sector Ownership}

Under centralized public-sector control, a government agency manages all roads, makes pricing decisions, and spends on road maintenance and construction based on a budget. This ownership scenario is constructed to replicate the existing road systems in U.S. urban areas. Therefore, marginal cost pricing is not assumed.

\subsubsection{Pricing Policy: Average Cost Pricing}

Under centralized control, users pay a distance-based toll for using the roads. This is similar to a fuel-tax except that the variation of fuel efficiency among vehicles is ignored. (Transaction costs of toll collection are assumed to be zero throughout).

$$
\tau_{a}^{i}=\rho_{1} \cdot\left(l_{a}\right)^{\rho_{2}}
$$

This pricing equation essentially represents an average-cost-pricing practice. Cost per kilometer of travel is the same no matter where or when trips occur. Revenue from each link is then collected, which is simply the product of the toll and annual traffic flow on the link:

$$
E_{a}^{i}=\tau_{a}^{i} \cdot\left(\psi \cdot f_{a}^{i}\right)
$$

\subsubsection{Investment Policy: Bottleneck Removal}

The bottleneck removal policy tends to favor expansion projects on road sections with the most severe congestion problems. A mathematical model is developed to describe this type of investment rule. In this model, total network revenue $\left(E_{T}\right)$ collected on all roads is managed by a centralized agency that is also responsible for its distribution. 


$$
E_{T a}^{i}=\sum_{a} E_{a}^{i}=\sum_{a} \tau_{a}^{i} \cdot\left(\psi \cdot f_{a}^{i}\right)
$$

All roads must be maintained at their current level of service. Total maintenance costs $\left(M_{T}\right)$ can be derived:

$$
M_{T a}^{i}=\sum_{a} M_{a}^{i}=\sum_{a} \mu \cdot\left(l_{a}\right)^{\alpha_{1}}\left(F_{a}^{i}\right)^{\alpha_{2}}\left(f_{a}^{i}\right)^{\alpha_{3}}
$$

A portion of the revenue is appropriated to defray maintenance costs. The remaining disposable revenue $\left(E_{D}\right)$ is used to expand capacity based on the current level of congestion as indicated by volume-to-capacity ratio $(S)$ on each road. Road $a$, which has the highest volume-tocapacity ratio in the network, is expanded first. The amount of capacity improvements is determined by the desirable volume-to-capacity ratio or the target level of service, $S^{*}$. The value of $S^{*}$ should depend on the performance of the network as a whole. The average $S$ of all roads is used.

$$
\begin{aligned}
& f_{a}^{i} / F_{a}^{i+1}=S^{*} \Rightarrow F_{a}^{i+1}=f_{a}^{i} / S^{*} \\
& S^{*}=\sum_{a} S_{a} / N
\end{aligned}
$$

The required expansion cost and the remaining revenue after expansion are, respectively:

$$
\begin{aligned}
& K_{a}^{i}=\phi \cdot\left(l_{a}\right)^{\sigma_{1}} \cdot\left(F_{a}^{i}\right)^{\sigma_{2}} \cdot\left(F_{a}^{i+1}-F_{a}^{i}\right)^{\sigma_{3}} \\
& E_{D}{ }^{i}=E_{D}{ }^{i}-K_{a}^{i}
\end{aligned}
$$


The second-most congested road is expanded next. The amount of capacity improvements, expansion costs and remaining revenue can be determined similarly. This process continues until the revenue is exhausted.

One assumption in the above procedure is the divisibility of road investments. In equation $4.9, F_{a}^{i+1}$ can take any positive value. A more realistic model would only allow for discrete road expansion. In the discrete case, the desirable new capacity is compared with the actual capacity if one, two or three lanes are added, which determines the number of lanes to expand and the resulting expansion costs.

\subsection{The "No-More-Freeway" Policy}

The "No-More-Freeway" policy builds on the pricing and investment policy under public-sector ownership, but departs from it in the following two aspects. First, an investment constraint is introduced that prohibits any forms of freeway capacity expansion. With this constraint, the capacity-expansion projects that would have been invested in based on the investment policy in Section 4.2.2 will no longer be funded under the "No-More-Freeway"

policy. Subsequently, the portion of the transportation revenue that would have been invested in more freeway capacity now needs to be reallocated, which is the other difference in the "NoMore-Freeway" policy. Because the travel demand models presented in Chapter 3 do not consider model choices in their present form, arterial streets will receive the extra revenue. Under this assumption, we can expect more arterial street capacity-expansion projects under the "No-More-Freeway" policy. The pricing policy remains average-cost-pricing resulting from fuel taxes, registration fees and other existing transportation taxes. 


\subsection{Pricing and Investment Policies under Private-Sector Ownership}

There are a large number of possible private-ownership regimes for a transportation network. There may be a private monopoly that controls all transportation facilities. The network may also be under a completely decentralized private-ownership structure, wherein each individual transportation facility is owned by an independent, private firm. This project focuses on the decentralized control scenario, as it represents a completely market-oriented approach (not necessarily the optimal private-ownership structure).

\subsubsection{Pricing Policy: Short-Run Profit-Maximizing}

When setting tolls, private roads under decentralized ownership take road capacity as a given and seek to maximize their short-run profits in an imperfectly competitive market. Because travel demand is elastic with respect to price, the profit-maximizing toll is constrained by the market. Competing links (often parallel roads serving the same origin-destination pairs) also restrict the price that a link can charge. It is anticipated that each link will have an objective function for profit maximization. However, depending upon assumptions of whether the firm fully understands market demand and how the firm treats the actions of competitors, the Nash equilibrium solution to the dynamic pricing game among private roads in a network may not be unique, or even exist. Whether this system converges upon an equilibrium solution, and whether that solution is unique, are both hard game-theoretic problems. This analysis does not take a game-theoretic approach to compute profit-maximizing prices, because any computable solution requires significant simplifying assumptions and unrealistic assumptions of the availability of information. 
The incompleteness of information is profound in a market comprised of non-cooperative competing roads. The situation of incomplete information is further aggravated by the fact that the demand function on one link depends on its previous investment decisions and the pricing/investment decisions made by its competing and complimentary links. Once a link has found a toll that it can neither raise nor lower without losing profit, it will be tempted to keep it. It is assumed that with uncertainty on the future pricing and investment behavior of other links, a link focuses on the observed historical demand corresponding to its previous tolls. The collective influence of the behavior of other links can be viewed as represented by the demand curve on the link. Links deal with system dynamics and uncertainty by adjusting their prices iteratively based on updated information about link travel demand after each time period. This price-probing behavior for profit-maximization is depicted in Figure 4-1. In each iteration, a link estimates a demand curve based on observed flows and previous tolls in the previous $k$ iterations (represented by crosses in the graph), and line-fitting methods. The $k$ previous prices fall into a range $\left[P_{l o w}, P_{H i g h}\right]$. The estimated demand curve can be extrapolated beyond this price range (dashed portion of the demand curve), but with increased uncertainty. This empirical demand curve is then used to find the optimal price $P^{*}$, which employs a standard quadratic optimization procedure. If $P^{*} \in\left[P_{\text {low }}, P_{H i g h}\right]$, like in case A, it determines the toll for the next period. Otherwise (e.g., case B), when data suggest $P^{*}$ is in a new price territory, the link will change price toward $P_{B}^{*}$ only by a conservative step $j$ to $P_{\text {Low }}(1-j)$. 


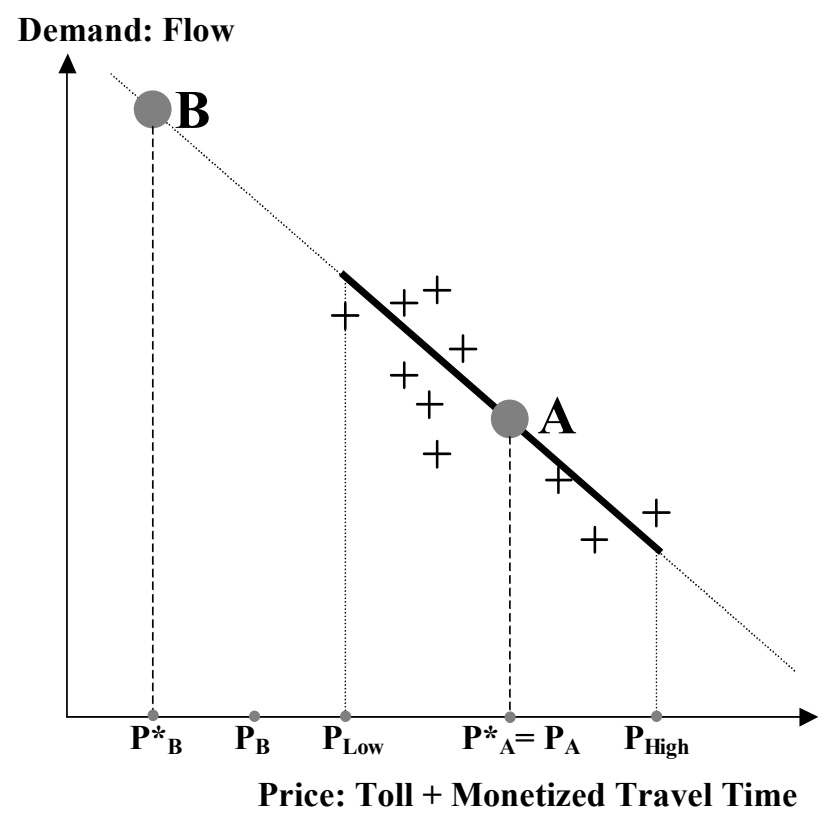

Figure 4.1. Profit-Maximizing Pricing under Uncertainty

This pricing rule assists private roads to maximize profit and keep the price changes smooth. It should be a plausible pricing rule when uncertainty about prices of other links and demand abound. When price regulation is present, the same pricing rule can be applied with a bound defined by the regulatory policy. A more intelligent link may realize that while it may have found a local maximum based on available information, because of the non-linearities comprising a complex network it may not be at a global maximum. Furthermore, other links may not be so firmly attached to their decision, and a periodic probing of the market landscape by testing alternative prices is likely. This, too, requires learning rules and should be explored in future studies. 


\subsubsection{Investment Policy: Long-Run Profit-Maximizing}

For profit-maximizing links, capacity expansion allows them to charge higher tolls, attract more traffic, or both. When the resulting increased profit exceeds the expansion cost and maintenance cost in the life cycle, links will build more capacity. When disposable link revenue is not sufficient to make the investment and the estimated rate of return is higher than the interest rate, links can and should borrow from others. When the estimated rate of return is lower than the interest rate, links either save the toll revenue in a bank or invest it in other sectors. These investment options are made available in the simulation model with a bank agent. The bank agent pays interest for savings and lends money to links with profitable projects. The bank agent has an additional rule that only currently profitable links can get loans. This rule is added to ensure links under decentralized control have positive cash flow.

While the combined costs of road expansion for a link can be calculated from cost functions, the expected amount of profit in the planning horizon (also 25 years) cannot be estimated with much certainty as other links may also expand capacity and prices can change significantly during the planning horizon. It is assumed that a link estimates the amount of profit from road expansion using the following method:

(1) Assume traffic increases by 3\% every year and the capacity and prices on other links remain unchanged;

(2) Compute travel time savings for users for a specific amount of capacity expansion (adding one more lane or two more lanes); 
(3) Run a travel demand model; re-distribute and re-assign traffic with reduced travel time and unchanged toll; and calculate the amount of profit gain throughout the planning horizon due to increased traffic on the link, $\pi_{1}$;

(4) Convert an individual traveler's time savings on the link immediately after expansion to a monetary value; increase the toll on the link by exactly the same amount which should keep traffic flow unchanged; and compute the profit gain throughout the planning horizon due to a higher toll on the link, $\pi_{2}$;

(5) The final estimated profit gain is $\max \left(\pi_{1}, \pi_{2}\right)$.

The rationale behind this profit estimation procedure is as follows: The extra profit gain due to road expansion and new investment comes from one or both of these two sources: increased traffic and increased toll. The above method finds the profit gains when only one of the two sources is exploited while the other is kept unchanged. Exploiting both sources at once indicates a tradeoff. While the final profit gain in this more complex case is expected to be higher than $\pi_{1}$ or $\pi_{2}$, and it is theoretically possible to identify the optimal toll level and maximum expected profit gain through optimization, it is computationally intractable to implement the optimization method for all links in a large network. Therefore, the profit estimate from the proposed method is an underestimate. The assumption that competing links do not expand capacity is necessary unless a clear leader in the road expansion game can be identified and more strategic investment decisions can be computed. This may overestimate the expected profit gain. On the other hand, the assumption that complementary links do not expand likely underestimates profits. 
Based on the discussion and analysis in this section, it is apparent that the combined globally optimal pricing and investment strategy for private roads in a decentralized road economy is very hard to determine due to uncertainty about future demand, others' strategies and network effects. It is therefore reasonable to doubt the likelihood that private roads will find the theoretically optimal investment level given the difficulty of that problem. The profitmaximizing pricing and investment strategies proposed in this section are hybrid strategies based on heuristic rules, learning and optimization principles.

\subsection{Pricing and Investment Policies under Mixed Ownership}

We model a type of mixed public-private ownership structure that is most relevant to the current practice in public-private partnerships. The scenario starts with a transportation network that is owned exclusively by a public-sector agency. The public road authority operates all existing public roads, and makes its own pricing and investment decisions as described in Section 4.2. According to the existing and anticipated travel demand patterns and cost estimates, the private sector decides whether or not to invest in candidate private toll-road projects, chooses a long-run profit-maximizing capacity level if an entry decision is made, and determines the short-run profit-maximizing tolls on private roads. If an initial market-entry decision is made and, consequently, a new, private toll road is constructed, the private road can adjust its toll and capacity levels adaptively based on profit objectives and all applicable regulatory policies. A regulator (e.g., state legislature) enacts policies regarding the entries and operations of private toll roads. 


\subsubsection{Regulatory Policy}

A private investor's decisions on market entry, toll and private-road capacity obviously depend on the legal and regulatory constraints, which need to be defined in the model. Results from the equilibrium model in Section 3 show that a private toll road can be very efficient (as measured by welfare standards) when there is a parallel public road, even though the privateroad toll and capacity are not regulated. Therefore, we define the simplest possible regulatory policy to study the welfare impact of private toll roads: (1) The private sector can only construct and operate toll roads with parallel alternative public roads, while the public alternative road will not be expanded for at least 10 years; (2) The private sector can only invest in new limitedaccess freeway capacity since no state currently has deployed technology to enable tolling on local arterial streets; (3) There is no restriction on market entry or a limit on the number of private toll-road projects each year; and (4) There is no regulation on price or capacity. However, the structure of the proposed evolutionary model is flexible enough to evaluate other regulatory policies or contracting agreements, such as price ceiling, profit cap, and limits on the rate of investment return.

\subsubsection{Market Entry of Private Tolled Freeways}

Private investment companies interested in transportation financing will base their market entry decisions on the estimated returns of investment of individual private-road projects. There are 1,363 limited freeway links on the road network, which implies 1,363 possible private-road projects. In real-world decisions, the investors should be able to eliminate a large number of feasible but non-profitable projects with statistics such as the current and future levels of congestion on the existing public roads. Their market entry decisions are modeled using a 
normative approach in this paper. The total profit a private investor can expect from a specific private-road project $a$ is:

$$
\pi\left(\tau_{a}^{t}, F_{a}^{0}\right)=\sum_{t=0}^{T}\left[\lambda^{t}(t) \cdot \tau_{a}^{t} \cdot f_{a}^{t}\right]-K_{a}^{0}\left(F_{a}^{0}\right)-\sum_{t=0}^{T}\left[\lambda^{t}(t) \cdot M_{a}^{t}\left(F_{a}^{0}\right)\right]
$$

$T$ is the expected life span of the project. The first term is the total revenue, the second term is construction cost according to equation 4.1, and the third term is maintenance cost according to equation 4.2. $\lambda$, the discount factor, so that the profit is expressed as the present value. It is assumed that $T=30$ years and the discount rate is $10 \%$, which defines discount factors in all years. The life span of a private toll road should be the minimum of the structural life and the concession period. For instance, the concession period is 30 years for Route-3 in Massachusetts, 35 years for SR-125 in California, 42.5 years for the Dulles Greenway in Washington, D.C., and 99 years for Route-895 in Virginia (FHWA 2006).

The maximum profit can be obtained at the optimal private-road capacity $\left(F_{a}{ }^{0}\right)$, and optimal tolls $\left(\tau_{a}^{\dagger}\right)$ in all future years within the life span of the project, subject to: (1). the future travel demand; and (2) the capacity and price choices of the parallel public freeway, which are both fixed based on the public pricing policy specified in Section 4.3 and the aforementioned regulatory policy. Recall that in Section 3 when the private and public roads both compete with price and capacity instruments, a game-theoretical problem is obtained. With the public pricing policy and the regulatory policy specified, the game-theoretical problem, which is extremely difficult (if not impossible) to solve on large network, drops to a non-linear optimization problem with a single objective (using $b$ to indicate the parallel public freeway):

$$
\text { Maximize: } \quad \pi\left(\tau_{a}^{t}, F_{a}^{0}\right)
$$

Subject to: 1. Traffic equilibrium between parallel private and public freeways 


\section{Construction and maintenance cost functions}

Based on the results from the current small-network equilibrium model (Zhang 2008), we developed the following algorithm to solve this maximization problem within the framework of the evolutionary model:

Step 1: Substitute construction and maintenance cost functions into the objective functions;

Step 2: Write $\tau_{a}{ }^{t}$ as a function of $F_{a}{ }^{0}$. This functional relationship still holds even when the parallel public freeway is not charging the welfare-maximizing toll (see details in Zhang and Levinson 2006). This guarantees the traffic equilibrium conditions. After this transformation, the original problem becomes an unconstrained single variable $\left(F_{a}{ }^{0}\right)$ maximization problem;

Step 3: The demand elasticity needs to be estimated. It determines the sensitivity of total traffic flows on the parallel private and public freeways to prices. The initial demand elasticities in the base year are computed by raising the equivalent distance-based toll on all existing freeways by $1 \%$ and observing the resulting changes in travel demand. In each future year, the demand elasticity estimates are updated as new tolls are set by the private roads and new traffic flows are obtained. The optimization problem herein is solved based on the available elasticity estimates at the time of market entry decisions.

Step 4: The unconstrained single-variable maximization problem is solved by a standard linesearch method with multiple initial trial solutions, and the maximum profit from the particular project is evaluated at the optimal future tolls and optimal immediate capacity level. 
Step 5: The same algorithm is implemented to solve all 1,363 (1,363 possible projects) market entry problems.

This algorithm is very efficient because the evaluation of objective function values for the line-search method does not involve any iterative procedures. Once the expected profits and immediate investment requirements (the construction costs) are determined, the rates of investment return on all candidate private toll-road projects can be computed. The private investment companies (modeled as a collective whole) will construct a private toll road if the investment return rate is higher than that of all alternative investment opportunities (assumed to be $6 \%)$.

\subsubsection{Investment Policy of Private Toll Roads}

It is assumed that once a market entry decision is made, a private toll road will be constructed and become operational in the next year (i.e., one-year design-build time). As travel demand grows and the private toll roads learn more information about the "actual" (in the model) demand elasticities, they may be expanded by the investor if capacity expansion is profitable. This dynamic capacity choice of private toll roads is considered by solving the same profitmaximizing problem in the "Market Entry" section for all existing private toll roads. If the new optimal capacity is higher than the current capacity, and if the return rate of the additional capacity investment is higher than the base rate $(6 \%)$, the particular private toll road will be expanded to the new optimal capacity. However, both the initial construction and subsequent expansion decisions are irreversible even if a private road is losing money. Although new capacity choices can be made at any time, it is assumed that they are considered once a year by 
the private investor because the public sector at most updates its transportation investment plan once a year.

\subsubsection{Pricing Policy of Private Toll Roads}

A new private toll road will charge the optimal first-year toll based on the solutions to the market-entry optimization problem during its first year of operation. However, the initially assumed demand elasticity for solving the optimal toll is unlikely to correspond to future demand patterns. Private toll roads can maximize their profits by learning demand responses adaptively as they accumulate data on previous tolls and previous traffic flows. It is assumed that private toll roads use historical toll (price) and flow (quantity) information up to five years back to estimate the underlying demand curves using a standard quadratic line-fitting technique. Using only the previous-year data will not fully utilize the information available, while using very old data may backfire as the demand curve itself for any individual road in a network shifts constantly. The causes of demand curve shifts include background traffic growth, new toll choices on other roads, and new capacity expansions on other roads.

Instead of using the optimal toll equation, which only considers the substitutional effect between parallel private and public freeways, to compute the constantly changing optimal tolls, private roads with learned knowledge about demand curves can adjust existing tolls by transforming the demand curves $(f(\tau))$ into profit curves $(\pi(\tau))$, and identifying the profitmaximizing tolls for the next year. This is similar to the adaptive price adjustment process on a completely private road network in Zhang and Levinson (2005a).

This adaptive learning process of private toll roads has been observed in reality. For instance, when the Dulles Greenway in Washington, D.C., opened in 1995, the one-way toll was 
$\$ 1.75$ per vehicle, but when traffic fell short of projected levels, the toll was reduced to $\$ 1$. This attracted more users but did not increase profit. Therefore, the toll was increased again to $\$ 1.15$ in 1997. Most recently, tolls were increased in 2004 and now have time-varying rates. (FHWA 2006).

\subsection{Socially Optimal Pricing and Investment Policies}

To better compare centralized and decentralized ownership structures, it is desirable to add to the comparison network performance with socially optimal pricing and investment policies. This optimal scenario provides the maximum possible welfare gains and serves as a benchmark.

\subsubsection{Pricing Rule: Marginal Cost Pricing Scheme}

The theoretical best pricing policy in a first-best environment is marginal cost pricing, which is estimated by the link travel time savings when one user is removed from the link. It should be noted that the true system-wide marginal cost of one additional trip on a link is different and can be higher or lower than the local link-level marginal cost (This is documented in Safirova and Gillingham 2003).

The capacity of a link is at optimum if the marginal cost of building one extra unit of capacity just equals the marginal benefit in a first-best scenario. In practical economic planning, the optimal capacity expansion project is often determined by benefit/cost analysis subject to budgetary constraints. The socially optimal investment policy defined herein is similar to the investment policy discussed in Section 4.1.2 except that budget balancing is no longer required. 
When there is still residual revenue after all capacity expansion projects with benefit-cost ratios larger than one are approved, this residual revenue is saved, instead of wasted on socially undesirable projects to eliminate any surplus. If there is insufficient revenue, it is borrowed from the future. When marginal cost pricing is adopted on a congested network, the occurrence of excessive revenue is quite possible.

\subsubsection{Investment Rule: System-Wide Benefit-Cost Analysis}

Different from bottleneck removal, benefit-cost analysis considers benefits as well as costs. It is important to establish a point of view for discussion of benefits and costs. The costs to society may not be considered as real costs to a company unless they are somehow internalized. Again, we consider a public agency and assume its goal is to maximize social welfare.

The life-cycle cost $\left(C_{a}\right)$ of a road expansion project can be estimated by the construction and maintenance cost functions.

$$
C_{a}=\phi \cdot\left(l_{a}\right)^{\sigma_{1}}\left(F_{a}^{0}\right)^{\sigma_{2}}\left(F_{a}^{1}-F_{a}^{0}\right)^{\sigma_{3}}+\sum_{i=1}^{y} \frac{1}{(1+R)^{y}}\left[\mu \cdot\left(l_{a}\right)^{\alpha_{1}}\left(F_{a}^{1}\right)^{\alpha_{2}}\left(f_{a}^{i}\right)^{\alpha_{3}}\right]
$$

Where:

$y \quad$ planning horizon or estimated life duration of the road

$R \quad$ interest rate

$F_{a}{ }^{0} \quad$ existing capacity

$F_{a}{ }^{l} \quad$ capacity after expansion

$f_{a}^{i} \quad$ traffic volume in year y: $f_{a}^{i}=(1+x)^{i} f_{a}^{0}$

$x \quad$ annual rate of traffic growth 
The life-cycle benefits of road expansion are usually manifold and some components are hard to quantify. Once a road is expanded, congestion level on the road being expanded will drop at least in the short run, resulting in less commute time, more reliable travel, fewer accidents, and reduced air pollution and energy consumption. The exact system-wide benefits are less clear because expanding a road tends to increase congestion on its complementary roads while attracting traffic away from its competitors. For simplicity, a formula for benefit estimation is specified which only considers travel time savings on the road being expanded. All non-local benefits, as well as impacts on accidents, pollution and fuel consumption, are ignored. Induced demand is also ignored.

$$
B_{a}=\sum_{i=1}^{y} \lambda \cdot \psi \cdot f_{a}^{i}\left\{\frac{l_{a}}{v_{a}^{0}}\left[1+\theta_{1}\left(f_{a}^{i} / F_{a}^{0}\right)^{\theta_{2}}\right]-\frac{l_{a}}{v_{a}^{1}}\left[1+\theta_{1}\left(f_{a}^{i} / F_{a}^{1}\right)^{\theta_{2}}\right]\right\}
$$

The optimal amount of capacity expansion can be identified for each road by maximizing the resulting benefit-cost ratio. This is a non-linear programming problem with a fairly complex objective function. However, roads can only be expanded by a fixed number of lanes, which helps us simplify the optimization problem. The benefit-cost ratios that correspond to adding one, two or three lanes can be evaluated quickly, and the maximum possible benefit-cost ratio $\left(B C^{*}\right)$, as well as the optimal number of lanes to be expanded $\left(F^{*}\right)$, identified for each road. Available funds should always be allocated to expand the road with the highest $B C^{*}$ by $F^{*}$ until exhaustion. 


\section{SIMULATION FINDINGS IN A HYPOTHETICAL URBAN AREA}

Chapters 3 and 4 complete the development of the ABSOLUTE model system for the analysis of short- and long-run transportation-land use impact of alternative transportation pricing and investment policies under different ownership regimes. This chapter demonstrates the model, and applies it to evaluate the "No-More-Freeway" policy in a hypothetical urban area with uniform initial land use patterns and a grid road network. For comparison, the existing transportation investment policy which continues freeway capacity expansion is also assessed. The impact indicators include the growth of the land use-transportation system under these alternative freeway policies, total travel time, and land use distribution characteristics.

\subsection{The Simulated Growth of a Hypothetical City}

The first graph (Year 0) in Figure 5.1 illustrates the initial land use and transportation network conditions in the hypothetical city. The city has a 10-by-10 grid network (100 nodes and 360 links). All links in the grid network are four kilometers in length and have an initial capacity of 735 vehicles per hour (This value corresponds to a one-lane road according to empirical regression analysis). The initial network is heavily congested with an average volume capacity ratio of 0.8 and an average speed of about $10 \mathrm{~km} / \mathrm{hr}$. The initial land use is uniform among all 100 network zones with 10,000 trips originating from and destined for each zone, respectively. OD demand is not fixed over the years due to changes in land use, road network and travel costs. Convergence of the ABSOLUTE model can be measured directly by the number of road capacity expansion activities and number of land use relocation activities in the urban system. 


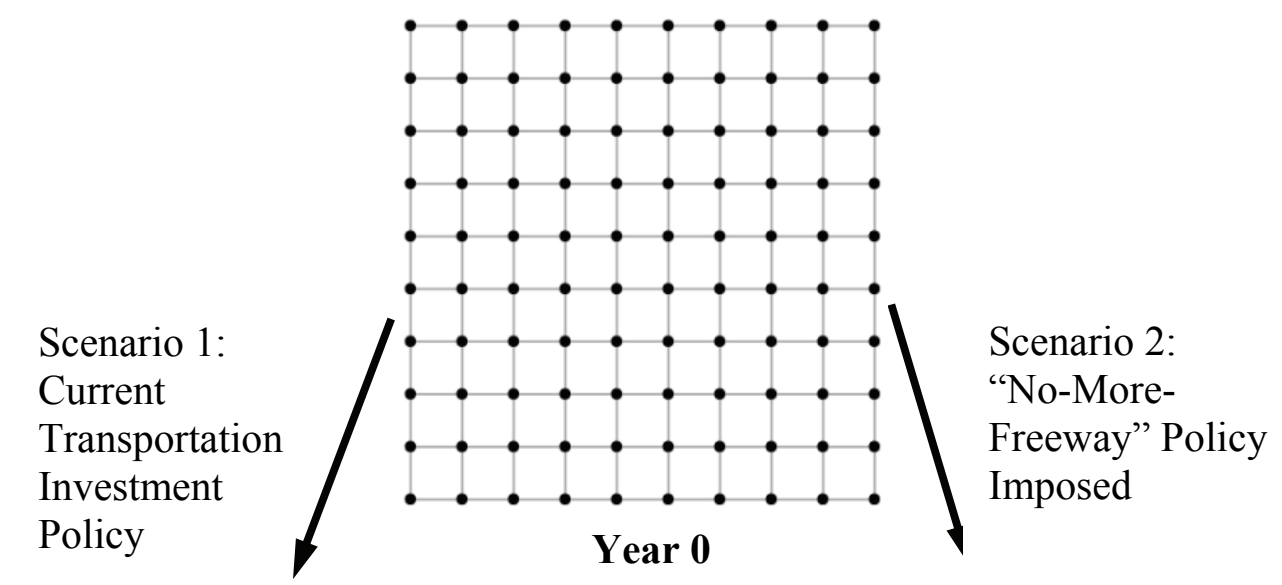

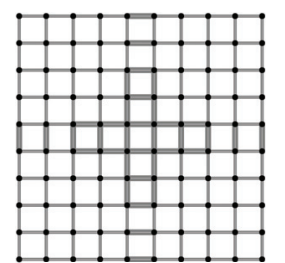

Year 1

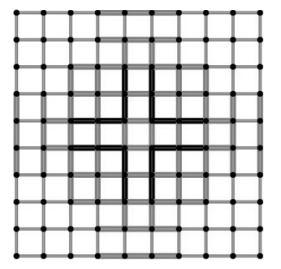

Year 5

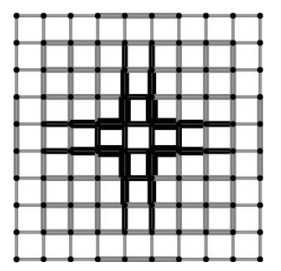

Year 20

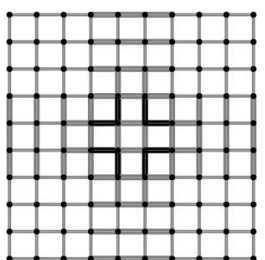

Year 2

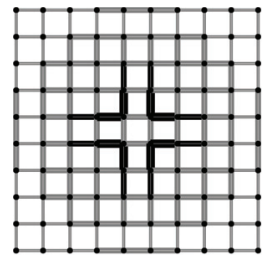

Year 10

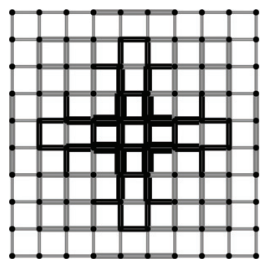

Year 50

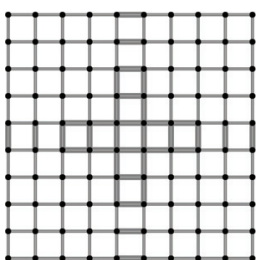

Year 1

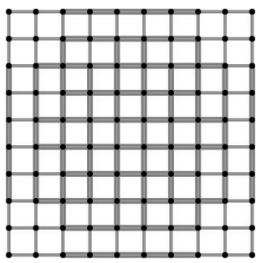

Year 5

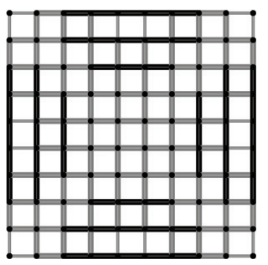

Year 20

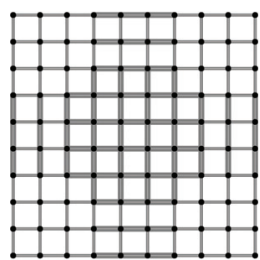

Year 2

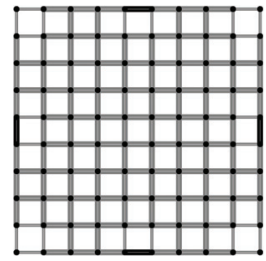

Year 10

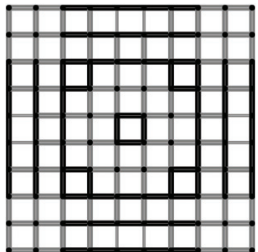

Year 50

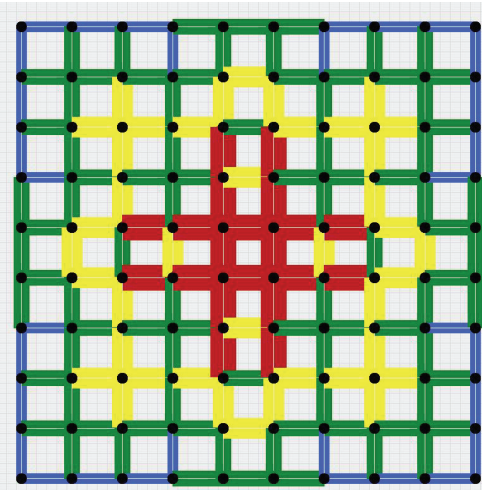

Equilibrium

Capacity (veh/hr)

- $0-1000$

$1000-2000$

$2000-3000$

$3000 \sim 4000$

$>4000$

$-0 \sim 1000$

$-1000 \sim 2000$

$\longrightarrow 2000 \sim 3000$

$3000 \sim 4000$

$>4000$

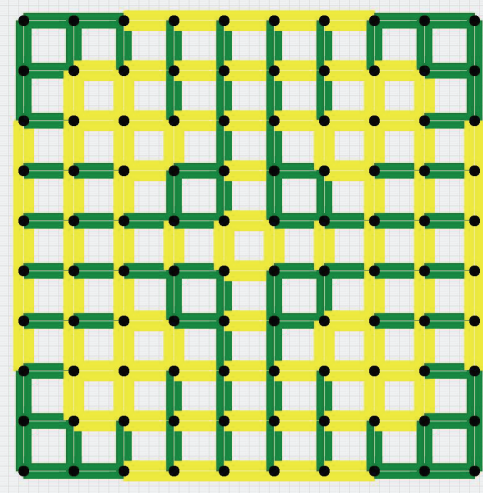

Equilibrium

Figure 5.1. Transportation Network Growth under Different Policies 
Two policy scenarios are tested in the chapter: the "No-More-Freeway" scenario described in Section 4.3 and the public-sector investment policy scenario described in Section 4.2 (current investment policy hereafter). The "No-More-Freeway" policy is enabled in this test with a constraint that prohibits road capacity from exceeding 3,000 vehicles per hour. The current practices in transportation investment primarily consist of fuel taxes for revenue and bottleneck removals for investment, which correspond well to the public-sector investment policy scenario. Therefore, the comparison made in this chapter can be viewed as a comparison between the current investment policies and the "No-More-Freeway" policy. The results presented herein are obtained from the hypothetical test urban area, and should not be generalized without future tests and analyses in real-world applications. The same initial land use and transportation network condition is specified for both the current investment and the "NoMore-Freeway" policy scenarios.

Figure 5.1 presents the transportation network changes over time (shown in black and white) predicted by the ABSOLUTE model, as well as the final transportation networks at longterm urban growth equilibria (UGE, shown in color). The color and thickness of roadway links represent the level of capacity, with green representing the lowest capacity category and red indicating the highest capacity category. The UGE is achieved when no significant land use or transportation network changes are predicted in five consecutive years. Scenario 1, current investment policy, reached equilibrium after 52 iterations (i.e., 52 simulated years). Scenario 2, "No-More-Freeway" policy, reached equilibrium after 66 iterations with most changes occurring in the first 52 iterations. When the land use and transportation network changes over time are compared between the two scenarios, only the first 52 iterations are compared for consistency. 
In Scenario 1, which allows freeway capacity expansion, one can clearly observe the emergence of major north-south and east-west freeway corridors $(>3,000$ vehicles/hour capacity levels) and major beltway corridors. Although the initial land use and network capacity are uniformly distributed in the hypothetical city, we can clearly see the emergence of the strong urban core in the center of the city with freeway capacity expansion. The central place theory and classic urban economics would also predict a strong urban core due to the overall ease of traveling to the center of the region. But this centralization tendency is clearly aggravated by the construction of high-capacity freeways. There is a positive feedback cycle: more land use is attracted to the urban core due to high accessibility; this creates congestion and attracts capacityexpansion projects along radial corridors to/from the center; and as capacity increases, even more land use is attracted to the urban core. This positive feedback reaches its limit when no additional land use can be accommodated in the urban center, or when no additional road capacity can be constructed due to high cost.

When the "No-More-Freeway" policy is implemented in Scenario 2, we expect more capacity expansion on arterial streets. The simulation results corroborate this, and the equilibrium transportation network consists of a much larger system of interconnected highcapacity arterial streets. In other worlds, the distribution of roadway capacity is much more even under the "No-More-Freeway" policy than that under the current investment policy. There does not seem to be a dominate corridor in the north-south, east-west or circular directions if the grid transportation network is divided into three portions (the center, the inner ring and the outer ring). It is the inner ring that has received the most transportation funding with the highest average roadway capacity (i.e., more yellow links in the result). It is interesting to observe that 
the transportation network growth originally starts from the center (see the evolutionary process from Year 0-50 in Scenario 2), though the center does not become dominant over time.

\subsection{Is Building More Freeways Counterproductive?}

From a transportation engineering point of view, it is important to compare the effectiveness of the two different investment policies. This comparison reveals the soundness of the "No-More-Freeway" policy. Figure 5.2 plots the total travel time in the urban system under the two policy scenarios over time. Since the initial urban system is very congested with an average volume to capacity ratio of 0.8 , the total vehicle hours traveled (VHT) is high at about 0.8 million hours. As transportation investments are made continuously in the system, the total travel time shows a declining trend under both policy scenarios. The increase of travel time that occurs between Years 3 and 5 results from induced demand after major capacity expansions in the first two years of simulation. In this test system, the "No-More-Freeway" policy happens to over-perform the current investment policy. The system of well-connected, more evenly distributed, high-capacity arterial streets is a better investment solution than the system of hierarchical road network with several freeways carrying the bulk of traffic. Future research should compare the two policy scenarios in real-world situations. 


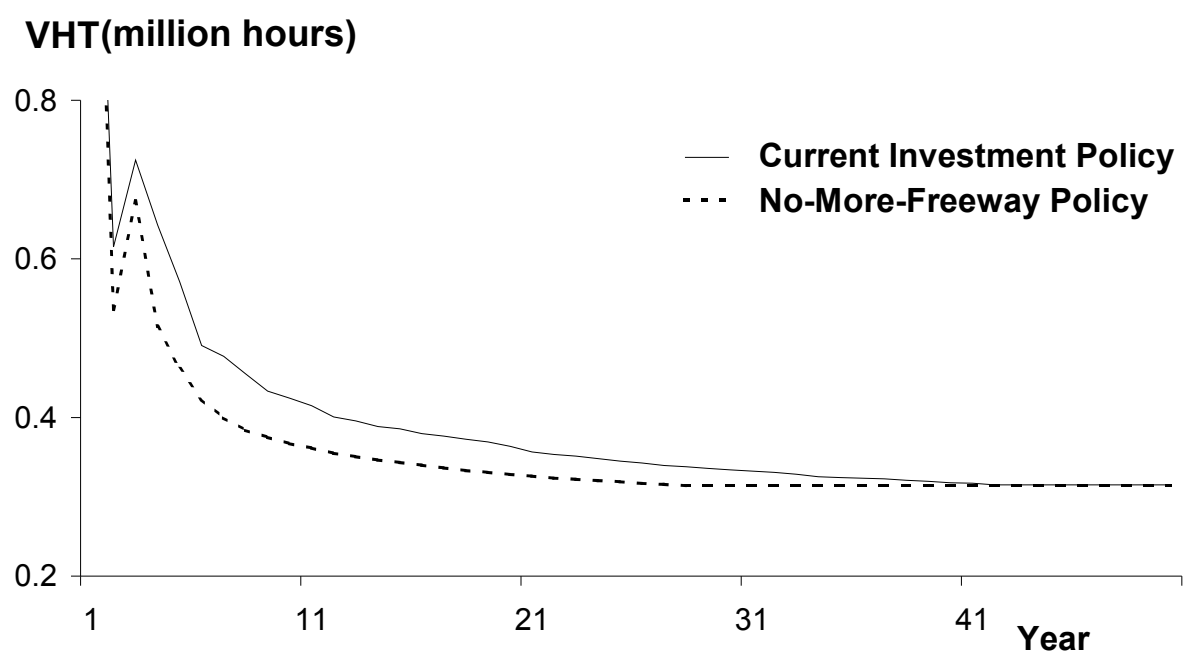

Figure 5.2. Vehicle Hours Traveled Under Different Policies

\subsection{The Land Use Impact of the "No-More-Freeway" Policy}

Households and firms should want to locate in the center and/or other areas of the city with superior accessibility to jobs and houses. Figure 5.3 illustrates the land use changes over time under the two policy scenarios, which is measured by the Gini coefficient. The Gini coefficient reflects the unevenness in the job and housing distributions among all land use cells. It ranges from 0 to 1 , with 1 indicating complete inequity (i.e., one land use cell has all the jobs or all the houses), and 0 indicating perfect equity (all land use cells have the same amount of jobs and houses). The equations for computing the Gini coefficients are available in Equations 5.1 and 5.2. 


$$
\begin{gathered}
G_{H}=\frac{\sum_{m=1}^{q} \sum_{n=1}^{q}\left|H_{m}-H_{n}\right|}{2 q \sum_{m=1}^{q} H_{m}} \\
G_{J}=\frac{\sum_{m=1}^{q} \sum_{n=1}^{q}\left|J_{m}-J_{n}\right|}{2 q \sum_{m=1}^{q} J_{m}}
\end{gathered}
$$

Where:

$G_{H} \quad$ Gini coefficient of residential distribution (House Gini);

$G_{J} \quad$ Gini coefficient of job distribution (Job Gini)

$H \quad$ Number of residents located in a particular land use cell

$J \quad$ Number of jobs located in a particular land use cell

$m, n \quad$ Indices of land use cells

$q \quad$ Total number of land use cells

The continuous increase in the values of the house and job Gini coefficients in both scenarios shows that residents and jobs are relocated throughout the simulation process, and that the land use cells that are able to attract more activities in the first several years will also attract more activities in later years (the rich get richer). Eventually, the trend of increasing concentration in residential and employment land use patterns stops as the city approaches the urban growth equilibrium due to congestion effects and the increasing costs of adding additional transportation capacity to the congested areas. We can also observe a higher degree of concentration of employment in both scenarios (comparing solid lines with the corresponding dashed line), which result in the emergence of major employment centers in the center of the city and possibly smaller employment centers in the inner ring. 


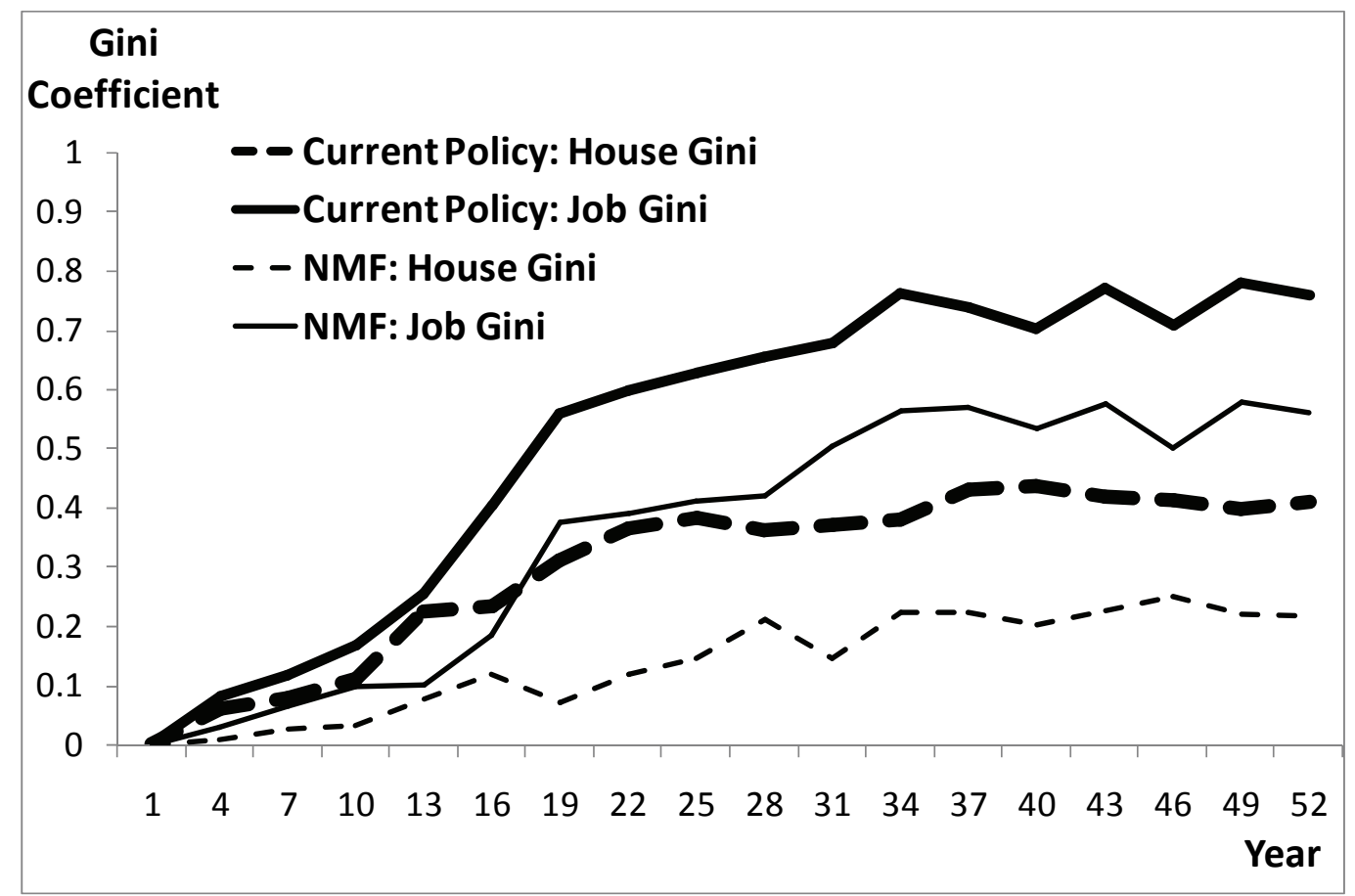

Figure 5.3. Land Use Changes Over Time

To assess the different impact of the two investment policies on land use, we can compare the two solid lines for employment location impact, or the two dashed lines for housing location impact. The Gini coefficients under the current investment policy are consistently larger than those under the "No-More-Freeway" policy. This indicates a higher degree of land use concentration under the current investment policy with its freeway capacity investment. A more even distribution of land use can be expected under the "No-More-Freeway" observations. This simulation finding seems to be supported by the observed land use differences between U.S. cities with major urban freeway corridors and European/Asian cities where freeways play a less important role in urban areas. 


\section{MORE PUBLIC FREEWAYS, MORE PRIVATE FREEWAYS OR NO MORE FREEWAYS}

The ABSOLUTE model is applied in this chapter to the Twin Cities metro area, and its capability for large-scale implementations demonstrated. Since the coefficients in the transportation supply and travel demand modules are calibrated from data collected in the Twin Cities, transportation network results of the ABSOLUTE model can be used for policy analysis, provided that the land use estimates are also correct. However, the land use module in the current ABSOLUTE model has not been calibrated for the Twin Cities, and is somewhat simplistic for real-world applications. Therefore, the land use module is not used in this test. Instead, the current and future land use patterns are estimated from the existing land use planning models by the Twin Cities metropolitan council (the metropolitan planning organization). In other worlds, land use is exogenously estimated for this application of the ABSOLUTE model.

\subsection{Five Alternative Policy Scenarios for Twin Cities, MN}

Five policy scenarios are designed for this application, including the "No-More-Freeway" policy. They differ in pricing schemes, investment rules and ownership structures, and correspond exactly to the five policy scenarios modeled in Chapter 4. The public-sector policy developed in Section 4.2 allows more public investment in freeway capacity expansion, and therefore is referred to as the "More-Public-Freeways" scenario in this chapter. It is also the closest to the status quo in transportation pricing and investment practice in U.S. metro areas. The "No-More-Freeway" policy in Section 4.3 does not allow either public or private freeway capacity expansion. The private-sector policy presented in Section 4.4 assumes all transportation facilities are privately owned by a large number of non-cooperative private investors. It is 
therefore referred to as the "Decentralized-Private" scenario. Private investments in both freeways and arterial streets can be expected in this scenario. The mixed-ownership policy, initially modeled in Section 4.5, assumes an initial transportation network that is owned exclusively by the public sector. The private sector is allowed to make investments in additional freeway capacity and charge tolls on the user of the new capacity, while the public sectors maintains all public roads and invests in capacity expansion on arterial streets only. This scenario is relevant to the private toll-road projects in the U.S. and other countries. We call this the "More-Private-Freeways" scenario. The last scenario focuses on "Socially Optimal" transportation pricing and investment policies, as described in Section 4.6. These five policy scenarios are summarized in Table 6.1.

Table 6.1. Five Policy Scenarios Tested for Twin Cities

\begin{tabular}{|l|l|l|l|}
\hline Policy Scenarios & Ownership & Investment & Pricing \\
\hline More-Public-Freeways & All public & Bottleneck removal & Average-cost pricing \\
\hline No-More-Freeway & All public & $\begin{array}{l}\text { Bottleneck removal on } \\
\text { arterial streets only }\end{array}$ & Average-cost pricing \\
\hline Decentralized-Private & $\begin{array}{l}\text { All private with } \\
\text { decentralized } \\
\text { competition }\end{array}$ & $\begin{array}{l}\text { Long-run profit } \\
\text { maximization }\end{array}$ & $\begin{array}{l}\text { Short-run profit } \\
\text { Maximization given } \\
\text { Existing network }\end{array}$ \\
\hline More-Private-Freeways & $\begin{array}{l}\text { Public ownership of } \\
\text { arterial streets and } \\
\text { current freeways } \\
\text { Private ownership of } \\
\text { new freeways }\end{array}$ & $\begin{array}{l}\text { Bottleneck removal on } \\
\text { arterials streets } \\
\text { Profit-max on freeways }\end{array}$ & $\begin{array}{l}\text { Average-cost pricing on } \\
\text { arterial streets } \\
\text { Profit-max on freeways }\end{array}$ \\
\hline Socially Optimal & Centralized & Welfare maximization & Marginal-cost pricing \\
\hline
\end{tabular}




\subsection{Net Social Benefits under Alternative Policy Scenarios}

All five scenarios are tested with the same initial land use and transportation network. The initial conditions are based on the observed existing land use patterns and transportation network status (as documented in the Twin Cities Metropolitan Council dataset). Each policy scenario is simulated twice and the average values from the two simulation runs are presented in this section. Results from the two runs are sufficiently close. Although additional simulation runs may provide even more stable results, the marginal benefit should not be significant. All simulation runs are conducted on a personal computer with a Dual-Core Intel processor at 3.2 GHz with about the average computing speed of standard personal computers. The maximum memory usage is around 1.2 gigabytes. On average, it takes about $12 \mathrm{CPU}$ minutes for each simulation iteration (i.e., simulation of one year of land use and transportation network evolution) and about $20 \mathrm{CPU}$ hours for each simulation run (we run 100 simulation iterations for each run). The urban growth equilibrium in the Twin Cities was not reached in any of the 10 simulation runs (five policies and two runs for each policy) due to the complexity of the system, but most significant changes occur during the first 15 iterations or first 15 simulated years. The traffic assignment step in the transportation module consumes a major portion of the running time.

Figure 6.1 illustrates the findings from the model, and summarizes the net social benefit over the first 15 years under the five policy scenarios. The net social benefit is defined as the sum of users' consumers' surplus and the road owners' suppliers' surplus. The consumers' surplus is computed based on the standard method of one-half. The suppliers' surplus is the total revenue minus total construction and maintenance costs. 


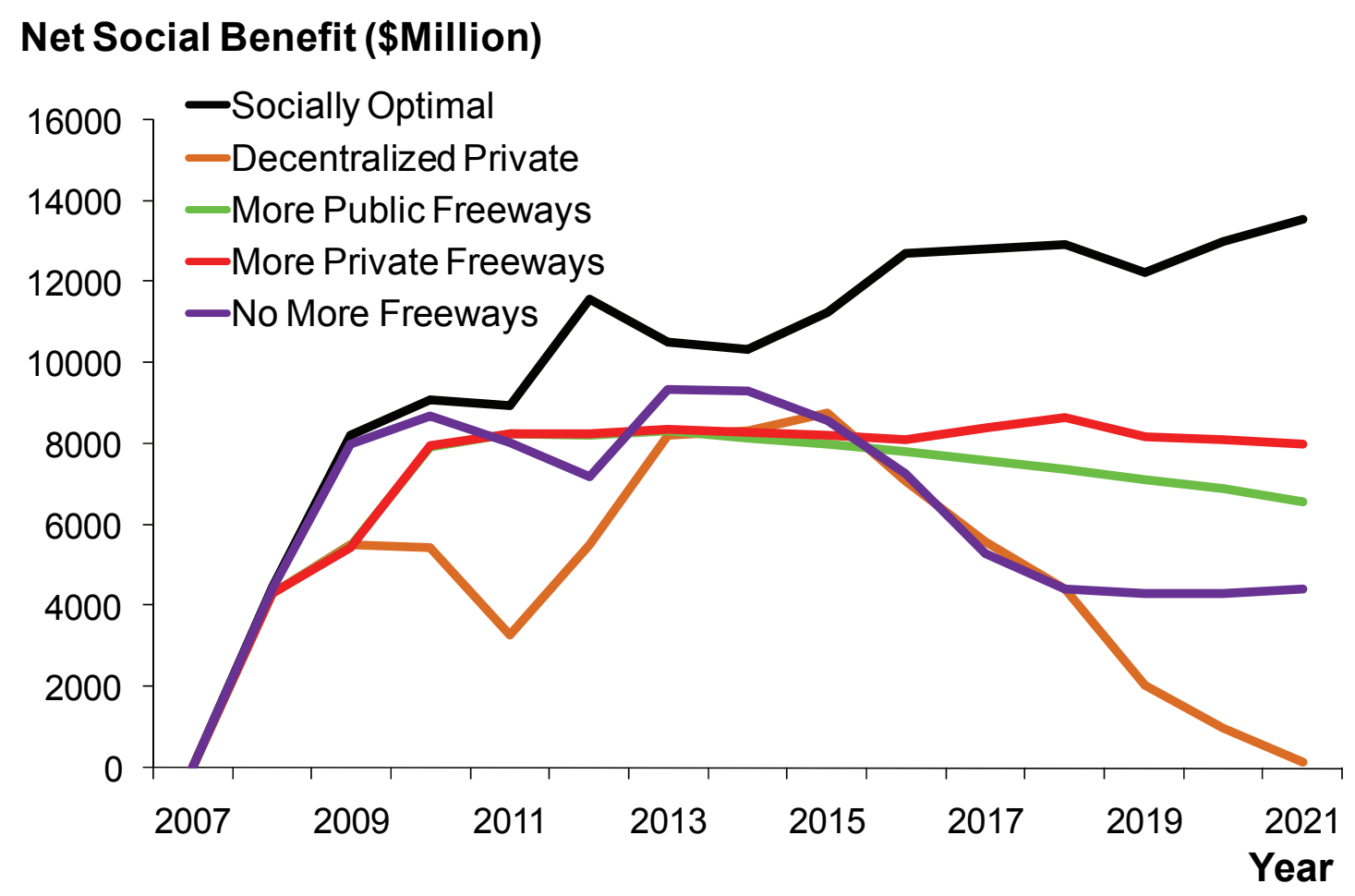

Figure 6.1. Net Social Benefits of Alternative Policy Scenarios

The socially optimal policy results in the maximum possible net social benefits in all years, which is expected. The "No-More-Freeway" policy (purple line) is actually the secondbest policy during most of the first eight years. This implies that in the immediate short term it is more cost-effective to invest in arterial street capacity than in freeway capacity. The model does not consider transit. But a reasonable hypothesis, given this finding, is that transit investment is also more cost-effective than freeway capacity investment. However, this hypothesis needs to be extensively tested after mode choice is introduced into the ABSOLUTE model system. In the long run, the ever-increasing overall travel demand (assumed to be 3\% per year) probably makes freeway capacity expansion a cost-effective investment again. It should be noted again that land use is fixed in this analysis because the land use module is not yet calibrated for the Twin Cities. But we can expect how endogenous land use will affect these results. If travelers and businesses 
are allowed to relocate themselves, they will choose to live closer to their employment/employees, which reduces overall travel demand. Therefore, the duration of the superiority of the "No-More-Freeway" policy over the other three non-optimal policy scenarios would be even longer.

It is also interesting to observe that the "More-Private-Freeways" policy is better than the "More-Public-Freeways" policy (compare the red and green lines). This is because the private sector is able to generate more revenue to make needed capacity expansion quickly with aggressive profit-maximizing tolls, and because the profit-maximizing tolls, compared to the average-cost tolls on public roads, are more consistent with the marginal cost pricing tolls and therefore more efficient in the short run. Additional findings from the comparison between these two policy scenarios are presented in the following section (Section 6.3).

The final observation in Figure 6.1 is that the "Decentralized-Private" policy exhibits the poorest performance over all. It is a market-based approach to transportation investment, wherein each road is owned by an independent private-sector company. The low net social benefit results from the monopoly power of these individual private roads even though there is competition between parallel roads. Each private road has some degree of spatially monopolistic power. For instance, there are usually very few or even just one road that provide access to the rest of the transportation network for certain users. The monopoly causes higher-than-optimal tolls in many scenarios, which explains the inefficiency of this policy scenario. For this market-based investment approach to become socially desirable, there needs to be proper regulation on pricing and even on investment. 


\subsection{Welfare Impact of Private-Sector Freeway Investment}

The comparison between the "More-Public-Freeway" and the "More-Private-Freeway" scenarios provides many interesting findings on the welfare and financial impacts of privatesector investment in freeway capacity. Because this is very relevant to the current debate on public-private partnerships, we decided to further discuss these findings in a separate section, even though this discussion is not directly related to the "No-More-Freeway" policy.

When the "More-Private-Freeway" scenario is evaluated, we found that following the opening of the road market to the private sector in the base year 2006, a total of 435 lanekilometers of private toll road would have been constructed by year 2020. Figure 6.2 illustrates the locations of these private tolled freeways (thicker lines). Their locations do not always overlap with the most congested freeway bottlenecks identified in the Twin Cities by the Minnesota Department of Transportation, as the prohibitively high construction cost at certain bottlenecks may render private toll projects unprofitable or less profitable than other investment opportunities.

It is interesting to note that, based on a novel formulation of the optimal network design problem, Davis and Sanderson (2001) estimate that in order to build our way out of congestion in the Twin Cities (i.e., all freeways operate at level of service $\mathrm{C}$ or higher), 1,844 lane-kilometers of new freeways would be needed to accommodate the travel demand predicted for the year 2020. A comparison between their estimate and the result herein suggests that even with profit levels largely unregulated, it should not be expected that the private-sector investment in freeway capacity alone will solve the congestion problem (they provide only one-fourth of the total capacity needed). The current and future urban land use characteristics, travel demand patterns, and facility supply cost together have determined that rational private investors will intentionally 
keep congestion at a certain level to achieve short- and long-run profit-maximizing objectives. This finding from the evolutionary model is consistent with the equilibrium model in Zhang and Levinson (2007), which shows that the private sector tends to under-build capacity and overcharge users. It should also be noted that even the socially optimal solution does not imply zero congestion. There are "optimal" levels of congestion for the private and public sectors, respectively.

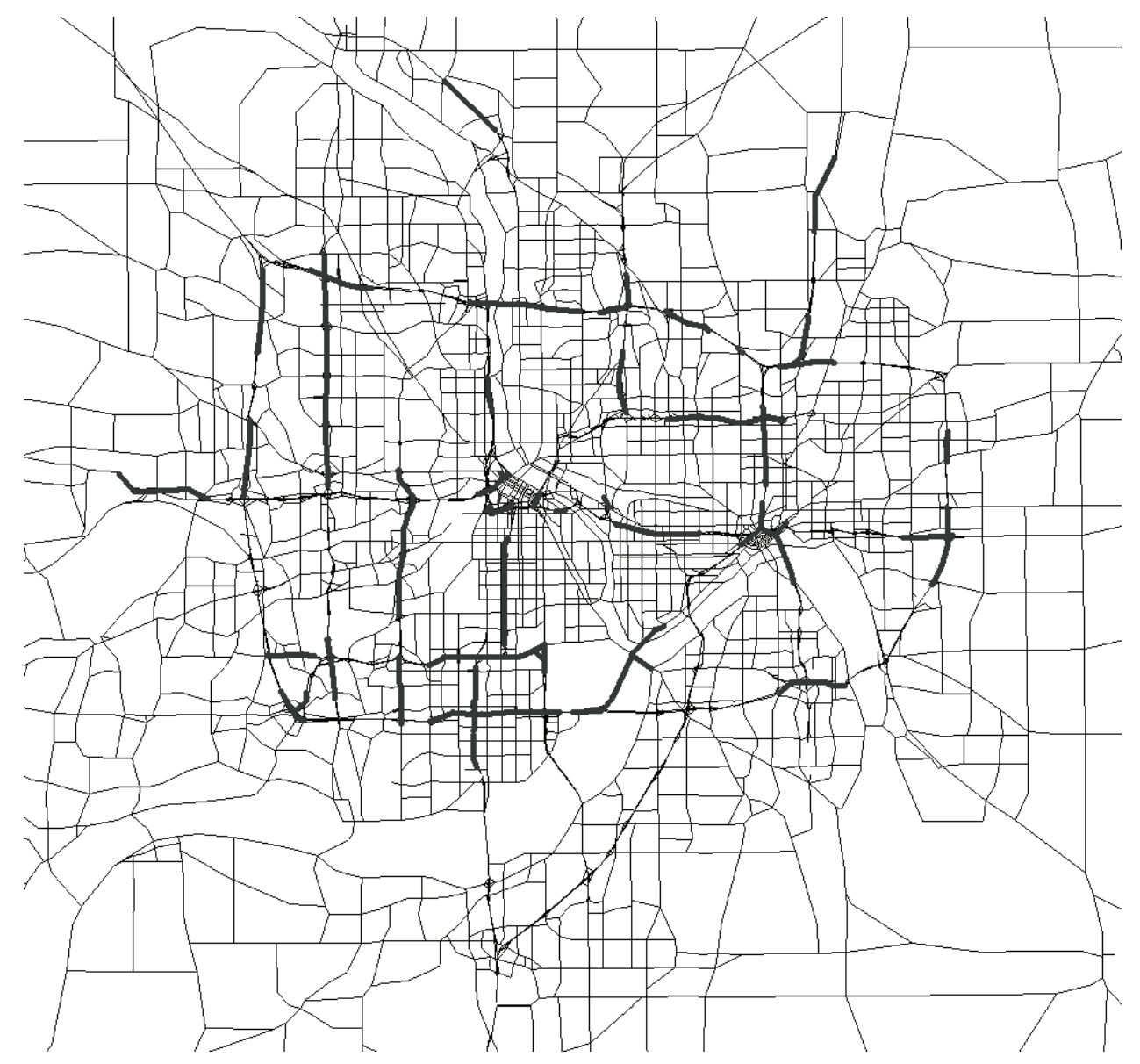

Figure 6.2. Year 2020 Location of the New Private Toll Roads 
The evolution of private freeway toll and freeway capacity is shown in Figure 6.3. As the overall travel demand grows at 3\% per year, more and more private toll-road projects would become profitable, as demonstrated by a steady increase in the total lane-kilometers of private toll roads. The profile of the average per-km toll of all private toll roads tells an interesting story. Recall that the initial toll for the first year of operation of any new private road is computed from the equilibrium toll equation, which only considers the competition between the private road and its parallel public freeway. That simplification results in an overestimation of the optimal toll level, as there are other public roads (i.e., arterial roads and parallel freeways further away) competing with the private road. However, by learning the actual travel demand responses, private roads in the model adjust their average toll from $\$ 0.20 / \mathrm{km}$ to about $\$ 0.15 / \mathrm{km}$ in six years. Eventually, the growing level of congestion will take effect and lead to a steady increase of the profit-maximizing toll level for private roads. Over the 15-year period, the average private road toll $(\$ 0.17 / \mathrm{km})$ is about seven times of the equivalent distance-based toll $(\$ 0.023 / \mathrm{km})$ on public roads. 


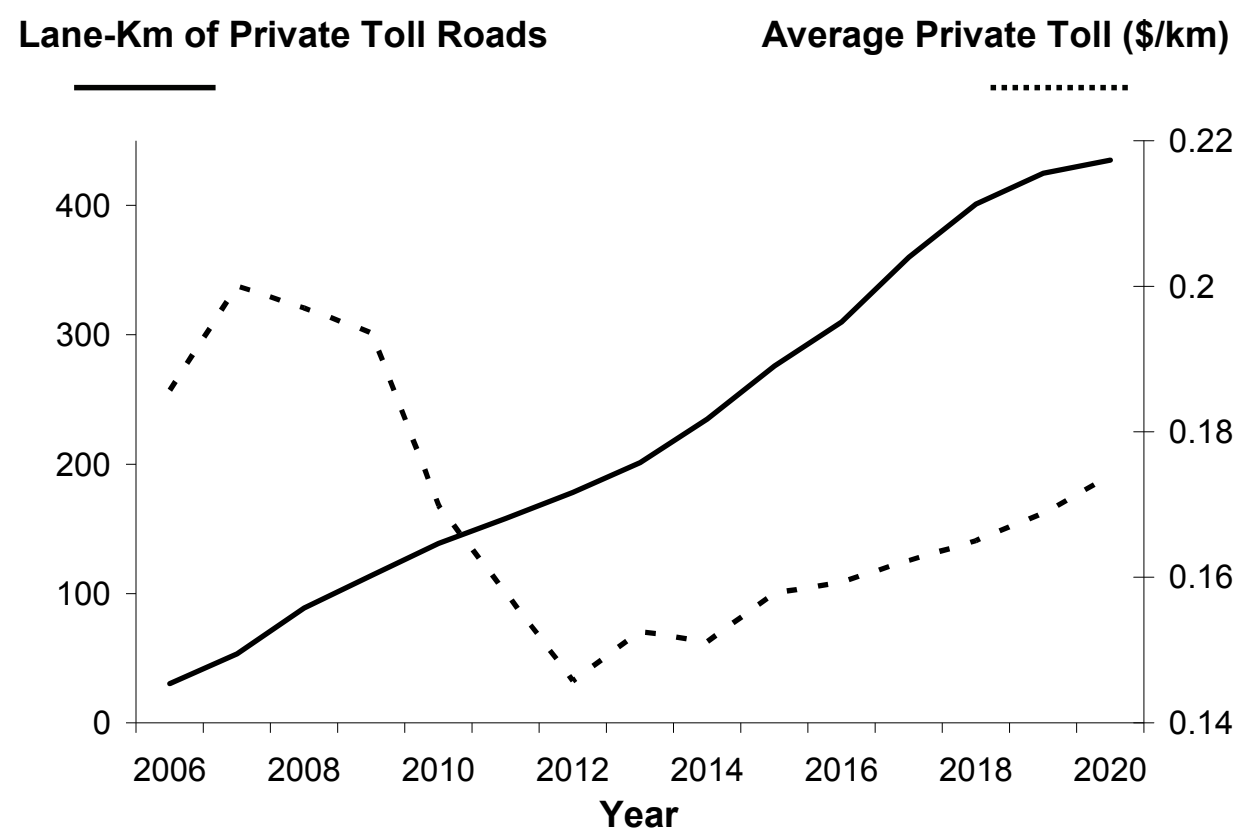

Figure 6.3. Lane-Km of Private Tolled Freeways and the Average Toll

\section{Percentage of Private Roads Making Profits}

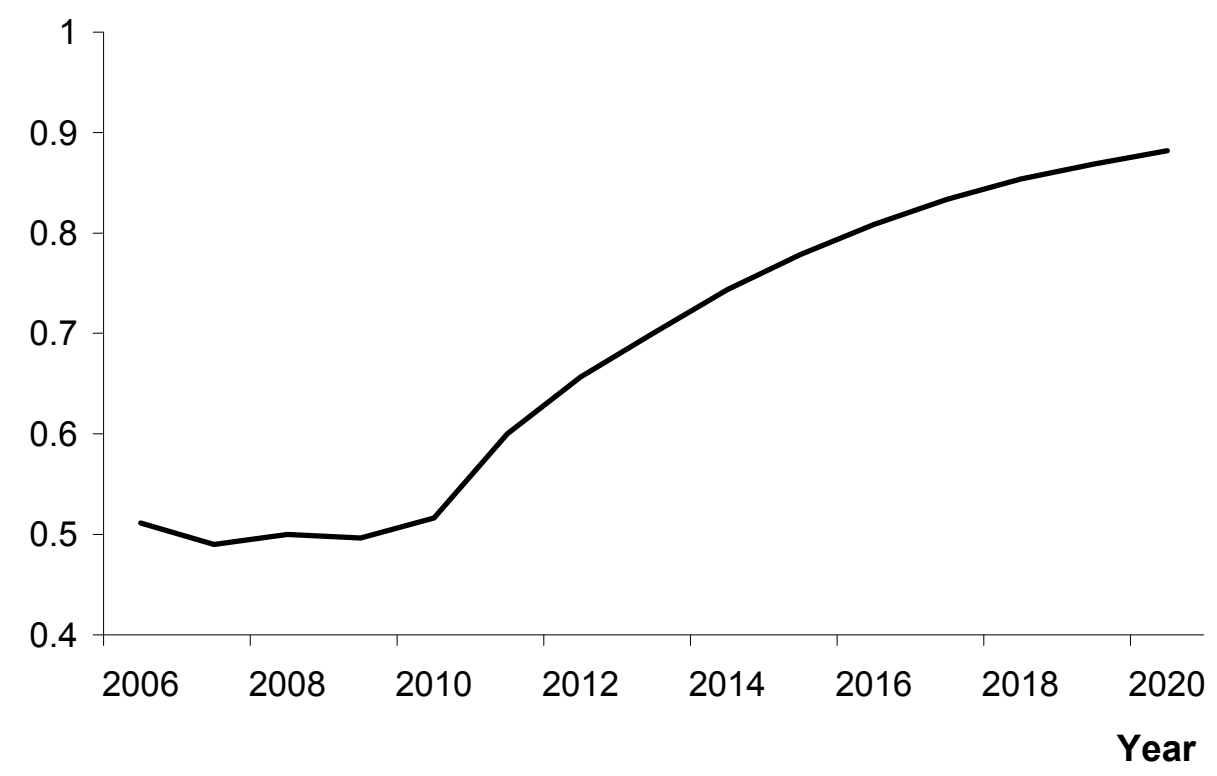

Figure 6.4. Profitability of Private Tolled Freeways Over Time 
The crucial factor that determines the private sector's interest in road financing and the public sector's regulation on private roads is the profitability of private roads. There are many examples of regulations on private tolls, rate of investment returns, and risk-sharing agreements between public and private entities when the profit level falls short of expectations. For instance, when increasing tolls to the maximum publicly acceptable level still could not produce profitable revenue streams in the opening years of the Dulles Greenway, the Virginia General Assembly allowed the speed limit to be increased from 55 to 65 miles per hour and approved an extension of the concession period for an additional 20 years. We calculated the annual profit for a private toll road using the difference between the annual revenue and the sum of the annual maintenance cost and the amortized construction cost. Results plotted in Figure 6.4 are against policies that provide subsidies or have provisions to increase the profit levels of private toll roads during the early years of their concession periods. The nature of annual traffic growth and the investor's tendency to initially charge higher-than-optimal tolls together determine that many private roads will operate at a deficit in their early years. According to the model, in 2006 just above half of all new private toll roads in the Twin Cities could make profits. However, over time an increasing percentage of private roads will start to see positive cash flows, and eventually make significant long-term profits. Our calculations actually show that the average private road in the Twin Cities constructed in the next 15 years would provide an average $18.2 \%$ of annual investment returns for the private investors over the assumed 30-year concession period.

Public policymakers may be concerned that negative cash flows in early years of tollroad operations would deter private sector capital from entering the road market. However, our results show that as long as private investors are interested in long-term profits, $\$ 19.5$ billion of private investments could be attracted to the Twin Cities under a free-entry minimum-regulation 
policy from 2006 to 2020, even though 51\% of toll roads would lose money in 2006 and $12 \%$ would still lose money in 2020 . To request immediate profits on private toll-road projects is an unreasonable request and should not be granted. Some might argue that without positive cash flow, the private sector will simply wait until the overall demand (or congestion) level is sufficiently high. This is a legitimate argument if there is only one private-sector monopoly that obviously has recall privilege (i.e., this sole investor can revisit a toll-road project anytime in the future without worrying about it being otherwise constructed). However, there is competition between multiple private-sector firms in real-world scenarios. For instance, FHWA has identified at least five U.S. and five foreign firms who are exploring or in the process of setting up infrastructure investment funds (FHWA 2006). Recent toll-road projects in Portland, OR, have also received multiple bids. When competition exists among multiple firms, they should be willing to commit to toll-road projects as long as their long-term profit-generating values significantly exceed the amount of investment. It is, therefore, recommended that toll-road policies for large-scale implementations be forged based on long-term profits and risks, not on short-term gains and fluctuations.

In terms of the welfare and financial impact of allowing the entrance of private toll roads in the Twin Cities, it is estimated that there would be a \$6.7-billion total welfare gain in the next 15 years ( $\$ 1.4$ billion/year gain in 2020 alone). Again the assumption is that the private-sector investment resources are allowed to freely enter the road market without any toll or capacity regulation as long as each private toll road has a parallel public freeway. The average rate of annual investment return for the private investors is $18.2 \%$. It is coincidental that the regulated maximum rate of private investment return is $18 \%$ for the Dulles Greenway, and $18.5 \%$ for California SR-125 (FHWA 2006). However, results from the model also show that at this level of 
investment return (and its implied levels of toll and capacity), only $16.4 \%$ of the welfare gain is distributed to the system users, while the private investors' profits contribute to the majority of the net social benefit. This raises the issue of optimal regulation on private toll roads, which should be explored in future research. 


\section{CONCLUSIONS}

This research develops an ABSOLUTE (Agent-Based Simulator of Land Use and Transportation Evolution) based on the land use-transportation co-evolution model developed in a previous research project (Zhang et al. 2009). The main modeling contribution of this project is the development of various transportation pricing and investment models under public, private, and mixed-ownership structures. This modeling innovation is an attempt to jointly consider pricing schemes, investment strategies and organizational structures in an integrated urban systems model, which has been understudied despite its obvious policy significance. The agentbased simulation system consists of a series of land use, travel demand, transportation cost, and transportation supply modules that can be empirically calibrated and validated. The transportation modules are calibrated in this project, but the task of calibrating the land use modules is left for future research due to the one-year project schedule. The successful development and demonstration of the ABSOLUTE system should encourage future endeavors in the long-run modeling of urban land use-transportation system dynamics.

The proposal of a "No-More-Freeway" transportation investment policy is discussed and evaluated with the ABSOLUTE model system. The research question is, What is the land use and transportation impact of not building any additional freeway capacity at all? With the "NoMore-Freeway" proposal as one of the alternative transportation investment policy scenarios, four additional policy scenarios are also developed, modeled and evaluated for comparison purposes: more public freeways, more private freeways, completely private ownership, and socially optional investment.

Results based on tests conducted for a hypothetical urban area with a small grid road network and uniform initial land use lead to the following conclusions. First, the "No-More- 
Freeway" policy produces more evenly distributed roadway capacity throughout the tested urban area. While the "More-Public-Freeway" scenario creates one major north-south and one major east-west freeway corridor that intersects at the center of the urban area (this corresponds to a system of two major radial freeways with freeway-to-freeway interchanges near the downtown area in real-world cities), under the "No-More-Freeway" policy, the singular freeway corridor is replaced by several parallel high-capacity arterial streets that serve all parts of the urban area. The resulting land use distribution as measured by the employment and housing distributions in land use cells is also less concentrated under the "No-More-Freeway" policy. This implies more evenly distributed employment and housing opportunities in the urban area. It is also found that the transportation network under the "No-More-Freeway" policy is actually more efficient from a mobility point of view than the current investment policy that invests in more freeway capacity. These conclusions based on the hypothetical urban system need to be tested again in future analyses in real-world urban systems.

The "No-More-Freeways" policy is also analyzed for a large-scale real world urban system: Twin Cities, MN, along with the other alternative transportation investment scenarios. Since the land use module is not calibrated, exogenous estimates of land use changes are used for this application. Despite this limitation, several interesting conclusions can be drawn. In the short run (the next eight years), the "No-More-Freeway" policy outperforms all other practical investment policies, such as more public investment in freeway capacity, more private investment in freeway capacity, or a completely market-oriented investment approach. This suggests that more investment in arterial streets is probably the more cost-effective investment strategy than more freeway capacities given the current land use and transportation systems in the Twin Cities. However, in the long run, continuous growth of travel demand will make 
freeway investment more cost-effective again unless there are even more efficient approaches (possibly transit investment, and/or more efficient land use).

This research can be extended in several ways. First, the ABSOLUTE model system can and should be further improved. Notably, a more sophisticated land use model, preferably a micro-simulation model for the consistency in model structure, can be introduced, calibrated and validated. Modules for mode choice are also important for the analysis of transit investment as an alternative to freeway capacity expansion. Second, the real-world transportation investment process involves a number of authorities (e.g., DOTs, MPOs, local government agencies, transit authorities, private investors), each of which has unique goals and approaches. To compare any alternative investment strategy (such as the "No-More-Freeways" policy) with the existing approach requires better modeling of the existing investment practices. An on-going research project led by the P.I. is addressing this issue. Finally, a more comprehensive analysis of the alternative transportation investment policies should be conducted for the Twin Cities and other urban areas. 


\section{REFERENCES}

Adams, J. (1999) Measuring the Connections: Highway Improvements and Land Development Patterns in the Greater Twin Cities Area, 1970-1995. Report submitted to the Center of Transportation Studies, University of Minnesota. www.cts.umn.edu.

Aghion, P. and P. Howitt (1998) Endogenous growth theory. Cambridge MA, MIT Press.

Arnott, R., de Palma, A., and Lindsey, R. (1992). Route choice with heterogeneous drivers and group-specific congestion cost. Regional Science and Urban Economics 22: 71-102.

Arnott, R., de Palma, A., and Lindsey, R. (1993). A structural model of peak-period congestion: A traffic bottleneck with elastic demand. American Economic Review 83: 161-179.

Aschauer, D (1989) Is Public Expenditure Productive? Journal of Monetary Economics Mar 23a(2): 177-200.

Axhausen, K.W., and Gärling, T. (1992). Activity based approaches to travel analysis: Conceptual frameworks, models and research problems, Transport Reviews 12(4): 323341.

Bar-Gera, H. and D. Boyce (2003) Origin-based algorithm for combined travel forecasting models. Transportation Research 37B(5): 405-22

Barker, T.C. and M. Robbins. (1975) A History of London Transport, Volume 1 and 2. Allen and Unwin, London

Barra, T. de la, et. al. (1989). TRANUS-J: Putting Large Models into Small Computers. Environment and Planning B 11: 87 - 101

Batty, M. and Longley, P. (1985) The Fractal Simulation Of Urban Structure / by Cardiff, Wales: Department of Town Planning, University of Wales Institute of Science and Technology, Papers in planning research; 92. 
Bernstein D, and Muller, J. (1993). Understanding the competing short-run objectives of peak period road pricing. Transportation Research Record 1395:122-128.

Boarnet, M. (1997) Infrastructure Services and the Productivity of Public Capital: The Case of Streets and Highways. National Tax Journal 50(1): 39-57, March, 1997

Boyce, D.E. (2002). Is the sequential travel forecasting paradigm counterproductive? Journal of Urban Planning and Development.128 (4), December 2002, 169-183.

Boyce, D.E., Farhi, R., and Weischedel, R. (1974). Optimal subset selection: Multiple regression, interdependence and optimal network algorithms. Springer-Verlag: New York, LLC.

Braid, R.M. (1996). Peak-load pricing of a transport facility with an unpriced substitute. Journal of Urban Economics 40:179-197.

BTS (Bureau of Transportation Statistics) (2002) Transportation Indicators http://www.bts.gov/transtu/indicators/Transportation_System_Extent and Use.html (Accessed June 12, 2002)

Bureau of Public Roads (BPR) (1964). Traffic assignment manual. Urban Planning Division, U.S. Department of Commerce, Washington, D.C.

Button (1998) Infrastructure investment, endogenous growth and economic convergence. Annals of Regional Science 32(1): 145-62

Button, K.J., and Verhoef, E.T. eds. (1998). Road pricing, traffic congestion and the environment: Issues of efficiency and social feasibility. Cheltenham: Edward Elgar.

Burns, L. (1979) Transportation, Temporal and Spatial Components of Accessibility, Lexington MA: Lexington Books. 
Caruthers, J.I., and Ulfarsson, G.F., (2001): Public Service Expenditures: The Influence of Density and Other Characteristics of Urban Development . The Pacific Regional Science Conference Organization. Conference in Portland OR July 2001

Christaller, W. (1966) Central places in southern Germany. Englewood Cliffs, New Jersey Prentice Hall (Translated by Carlisle W. Baskin)

Clark, C. (1968) Population Growth and Land Use, Macmillan, London.

Conder, S. (2001) Metroscope Documentation. Technical Report, Portland Metro.

Cournot, A. (1838). Researches into the Mathematical Principles of Wealth. Paris: Hachette.

Davis, G., and Sanderson, K. (2001). Building our way out of congestion: Highway capacity for Twin Cities. Minnesota DOT Research Report MN/RC - 2002-01.

De Borger, B., Dunkerly, F., and Proost, S. (2006). The interaction between tolls and capacity investment in serial and parallel transport networks. CES Discussion Paper. DPS 06-17. http://www.econ.kuleuven.be/CES/discussionpapers/Dps06/Dps0617.pdf (accessed December 15, 2006).

De La Barra, T. (1989) Integrated Land Use and Transport Modeling. Cambridge: Cambrige University Press. $59 \sim 64$.

de Palma, A. (1992). A game-theoretic approach to the analysis of simple congested networks. American Economic Review 82(2): 494-500.

de Palma, A., Lindsey, R. (2000). Private toll roads: Competition under various ownership regimes. Annals of Regional Science 34: 13-35.

de Palma, A., and Lindsey, R. (2002). Private roads, competition, and incentives to adopt timebased congestion tolling. Journal of Urban Economics 52: 217-241. 
de Palma, A. (1992). A game-theoretic approach to the analysis of simple congested networks. American Economic Review 82(2): 494-500.

de Palma, A., and Leruth, L. (1989). Congestion and game in capacity: A duopoly analysis in the presence of network externalities. Annales D'Économie et de Statistique 15/16: 389-407.

de Vany, A., Saving, T. (1980). Competition and highway pricing for stochastic traffic. Journal of Business 53: 45-60.

Dupuit, J. (1844). On the measurement of the utility of public works. Reprinted in Munby, D. (editor), Transportation: Selected Readings. 1968.

Economides, N. (1996). The economics of networks. International Journal of Industrial Organization 16 (4): 673-699.

Ewing, R. (1997) Is Los Angeles Style Sprawl Desirable. Journal of the American Planning Association 63(1): 107-126.

Federal Highway Administration (2006). Public-private partnerships case studies. Webpage accessed on 10/30/2006, http://www.fhwa.dot.gov/ppp/case_studies.htm.

Fulton, L.M., Noland, R.B., Meszler, D.J. and J.V. Thomas (2000) A statistical analysis of the induced travel effects in the US Mid-Atlantic region. Journal of Transportation and Statistics 3(1): 1-14

Garrison, W.L. and D.F. Marble (1965) A prolegomenon to the forecasting of transportation development. Office of Technical Services, US Department of Commerce, US Army Aviation Material Labs Technical Report

Gini, Corrado (1936) On the Measure of Concentration with Espacial Reference to Income and Wealth. Cowles Commission 
Glasser, G. J. (1962) Variance Formulas for the Mean Difference and Coefficient of Concentration. J. Amer. Stat. Assoc., Vol 57, pp. 648-654

Gomez-Ibanez, J. (1999). Pricing. In Gomez-Ibanez, J., Tye, W.B., and Winston, C., (editors), Essays in Transportation Economics and Policy: A Handbook in Honor of John R. Meyer. Brookings Institution Press: Washington DC.

Gomez-Ibanez, J., and Meyer, J. (1993). Going private: The international experience with transport privatization. Brookings Institute: Washington, DC.

Gordon, P., and Wong, H.L. (1985) The Costs of Urban Sprawl - Some New Evidence. Environment and Planning A 17(5): 661-666.

Gordon, P., and Richardson, H.W. (1997) Are Compact Cities a Desirable Planning Goal? Journal of the American Planning Association 63(1): 95-106.

Giuliano, G. (2004). Land Use Impacts of Transportation Investments: Highway and Transit. In Hanson, S. and Giuliano, G. (eds.), The Geography of Urban Transportation. New York: Guilford Press.

Greene, D.L. (1997) Sustainable transport. Journal of Transport Geography 5(3):177-190.

Gramlich, E. (1994) Infrastructure investment: a review essay. Journal of Economic Literature 32: $1176-1196$

Gregor, B. (2006). The Land Use Scenario DevelopeR (LUSDR): A Practical Land Use Model Using a Stochastic Microsimulation Framework. Submitted for Presentation at the 86th Annual Meeting of the Transportation Research Board.

Grübler, A. (1990) The rise and fall of infrastructures: dynamics of evolution and technological change in transport. Heidelberg: Physica-Verlag 
Gwilliam, K.M. (1997). Sustainable transport and economic development. Journal of Transport Economics and Policy 31: 325-330.

Haynes, K.E. and A.S. Fotheringham (1984) Gravity and Spatial Interaction Models. Beverly Hills, CA: Sage Publications

Haj-Salem, H. and Papageorgiou, M. (1995) Ramp metering impact on urban corridor traffic:

Field results. Transportation Research Part A 29(4): 303-319.

Handy, S. (1993) Regional Versus Local Accessibility: Implications for Nonwork Travel.

Transportation Research Record 1400: 58-66.

Hansen, W.G. (1959) How Accessibility Shapes Land Use. Journal of the American Institute of Planners 25: 152-166.

Hanson, S. and Giuliano, G. (eds.) (2004). The Geography of Urban Transportation. New York: Guilford Press.

Hanson, S., and M. Schwab (1987) Accessibility and Intra-urban Travel. Environment and Planning A 19(6): 735-748.

Hagerstrand, T. (1970). What about people in regional science? Papers and Proceedings of the Regional Science Association 24: 7-21.

Hutchinson, B. G. (1974) Principles of Urban Transportation Systems Planning. New York: McGraw-Hill

Johansson, B., Karlsson, C., and Westin, L. eds. (1993). Patterns of a Network Economy. Springer-Verlag: Berlin.

Jones, P., ed. (1990). Developments in dynamic and activity-based approaches to travel analysis. Brookfield, Vt.: Avebury. 
Kahn, A.E. (1988). The economics of regulation: Principles and institutions. MIT Press: Cambridge, MA.

Keeler, T.E., and Small, K.A. (1977). Optimal peak-load pricing, investment and service levels on urban expressways. Journal of Political Economy 85(1): 1-25.

Kitamura, R.(1988). An evaluation of activity-based travel analysis. Transportation15: 9-34.

Knight, F.H. (1924). Some fallacies in the interpretation of social cost. Quarterly Journal of Economics 38: 582-606.

Kraus, M. (1981). Scale economies analysis for urban highway networks. Journal of Urban Economics 9: 1-22.

Krugman, P. (1996) The Self-Organizing Economy. New York: Blackwell

Langton, C. ed. (1989). Artificial life. Addison-Wesley Publishing Company: Redwood City, CA.

LeBlanc, L.J. (1975). An algorithm for the discrete network design problem. Transportation Science 9: 183-199.

Lee, C. (1973) Models in Planning. London: Pergamon Press.

Levinson, D., and A. Kumar (1995) A Multimodal Trip Distribution Model: Structure And Application. Transportation Research Record 1466:124-31.

Levinson, D. (1998) Accessibility and the Journey to Work. Journal of Transport Geography 6(1): 11-21.

Levinson, D., and Zhang, L. (2006). Ramp meters on trial: Evidence from the Twin Cities metering holidays. Transportation Research 40A (10): 810-828. 
Levinson, D., Zhang, L., Das, S., and Sheikh, A. (2004). Evaluating the effectiveness of ramp meters. In Gillen, D. and Levinson, D. (editors), Assessing the Benefits and Costs of Intelligent Transportation Systems, Kluwer Academic Publishers.

Levinson, D. (1995) An evolutionary transportation planning model. Transportation Research Record 1493: 64-73

Levinson, D. (1999). Tolling at a frontier: A game theoretic analysis. Proceedings of the 14th International Symposium on Transportation and Traffic Theory: 173-187.

Levinson, D. (2000). Revenue choice on a serial network. Journal of Transport Economics and Policy 34,1: 69-98.

Levinson, D. (2005). Micro-foundations of Congestion and Pricing: A Game Theory Perspective. Transportation Research part A Volume 39, Issues 7-9, August-November 2005, Pages $691-704$

Levinson, D., and Yerra, B. (2002). Highway costs and the efficient mix of state and local funds. Journal of the Transportation Research Board 1812: 27-36.

Levinson, D., and Gillen, D. (1998). The full cost of intercity highway transportation. Transportation Research 3D: 207-223.

Levinson, D. and R. Karamalaputi (2003) Induced supply: a model of highway network expansion at the microscopic level. Journal of Transport Economics and Policy 37(3): $297-318$

Levinson, D., and Montes de Oca, N. (2006). Network expansion decision-making in the Twin Cities. In TRB 85th Annual Meeting Compendium of Papers CD-ROM.

Liu L.N., and McDonald J.F. (1999). Economic efficiency of second-best congestion pricing schemes in urban highway systems. Transportation Research 33B:157-188. 
May, D., and H. Bogenberger (1999) Advanced Coordinated Traffic Responsive Ramp Metering Strategies. California PATH working paper UCB-ITS-PWP-99-19.

Miyagi, T. (1998) A spatial computable general equilibrium approach for measuring multiregional impacts of large scale transportation projects. Network Infrastructure and the Urban Environment, Springer, 224-44

Miyao, T. (1981) Dynamic analysis of the urban economy. Academic Press, New York

Meng, Q., Yang, H., Bell, M.G.H. (2001). An equivalent continuously differentiable model and a locally convergent algorithm for the continuous network design problem. Transportation Research Part 35B: 83-105.

Mohring, H., and Harwitz, M. (1962). Highway Benefits: An Analytical Framework. Nothwestern University Press.

Mokhtarian, P.L., and Chen, C. (2004). TTB or not TTB, that is the question: A review and analysis of the empirical literature on travel time (and money) budgets. Transportation Research 38(9-10)A: 643-675.

Muth, R.F. (1969) Cities and Housing. Chicago: University of Chicago Press.

Nadiri, M. Ishaq and T. Mamuneas (1996) Contribution of highway capital to industry and national productivity growth. Federal Highway Adminstration

Nagurney, A. (1993). Network economics: A variational inequality approach. Kluwer Academic Publishers: Norwell, MA.

New Jersey Office of State Planning (1996) Projecting municipal road costs under various growth scenarios. Document Number 109

Newman, M.E.J. (2001) The structure and function of networks. Computer Physics and Communications 147: 40-45 
Neuburger, H. (1971). User benefits in the evaluation of transport and land use plans. Journal of Transport Economics and Policy 5(1): 52-75.

Noland, R.B. (1998) Relationship between highway capacity and induced vehicle travel. Transportation Research Board $78^{\text {th }}$ Annual Meeting Preprint CD-ROM, Transportation Research Board, National Research Council, Washington DC

Payne-Maxie Consultants (1980) The Land Use and Urban Development Impacts of Beltways, Final Report No. DOT-0S-90079, U.S. DOT \& DHUD, Washington, D.C.

Parthasarathi, P., Levinson, D., and R. Karamalaputi (2003) Induced demand: a microscopic perspective. Urban Studies 40(7): 1335-1353

Pas, E.I. (1985). State of the art and research opportunities in travel demand: another perspective. Transportation Research 21A: 431-438.

Peat F.D. (2002) From certainty to uncertainty: the story of science and ideas in the twentieth century. National Academy Press: Washington DC p.xiii

Pigou, A.C. (1920). The Economics of Welfare. Macmillan.

Poorzahedy, P., Turnquist, M.A. (1982). Approximate algorithms for the discrete network design problem. Transportation Research B 16: 45-56.

Roberts, M and D. Simmonds (1997). A strategic modeling approach for urban transport policy development. Traffic Engineering and Control 38(7): 377-384.

Ross, G. (1996). Roads in market economy. Aldershot: Avebury.

Safirova, E.A., and Gillingham, K.T. (2003) Measuring marginal congestion costs of urban transportation: Do networks matter? Discussion Paper 03-56. Resources for the Future, Washington, DC..

Schelling, T. C. (1969) Models of segregation. American Economic Review59(2): 488- 93 
Schmanske, A. (1993). A simulation of price discriminating tolls. Journal of Transport Economics and Policy 27: 225-235.

Sheffi, Y. (1985) Urban transportation networks. Prentice-Hall, Englewood Cliffs, NJ

Small, K.A. (1982). The scheduling of consumer activities: Work trips. American Economic Review 72: 467-479.

Small, K.A. (1992). Using the revenues from congestion pricing. Transportation 19: 359-381.

Small, K.A. (1999). Economies of scale and self-financing rules with non-competitive factor markets. Journal of Public Economics 74: 431-450.

Small, K.A., Winston, C.M., and Evans, C.A. (1989). Road work. Washington, DC:

Brookings Institution.

Small, K.A., and Yan, J. (2001). The value of "value pricing" of roads: Second-best pricing and product differentiation. Journal of Urban Economics 49: 310-336.

Stouffer S.A. (1940). Intervening opportunities: A theory relating mobility and distance. American Sociological Review 5, pp. 845-867.

Smock, R.J. (1962) An iterative assignment approach to capacity restraint on arterial networks. Highway Research Board Bulletin 156: 1-13

Strathman, J.G., Dueker, K.J., Sanchez, T., Zhang, J., and A.E. Riis (2000) Analysis of induced travel in the 1995 NPTS. Center for Urban Studies, Portland State University

Sussman, J. (2000). Introduction to transportation systems. Boston, MA: Artech House.

Taffe, E.J., Morrill, R.L., and P.R. Gould (1963) Transport expansion in underdeveloped countries: a comparative analysis. Geographical Review 53 (4): 503-29

Texas Transportation Institute (2005). Urban Mobility Report. Texas Transportation Institute Report. 
Train, K.E. (1991). Optimal regulation: The economic theory of monopoly. MIT Press: Cambridge, MA.

Vaughan, R. (1987) Urban Spatial Traffic Patterns, Pion Limited, London

Verhoef, E.T. (2002). Second-best congestion pricing in general networks: Heuristic algorithms for finding second-best optimal toll levels and toll points. Transportation Research $36 B$ : 707-729.

Verhoef, E.T., Nijkamp, P., Rietveld, P. (1996). Second-best congestion pricing: The case of an untolled alternative. Journal of Urban Economics 40: 279-302.

Verhoef, E.T., and Rouwendal, J. (2004). Pricing, capacity choice, and financing in transportation networks. Journal of Regional Science 44 (3): 405-435.

Verhoef, E.T., and Small, K.A. (2004). Product differentiation on roads: Second-best congestion pricing with heterogeneity under public and private ownership. Journal of Transport Economics and Policy 38: 127-156.

Vickery, W. (1963). Pricing in urban and suburban transport. American Economic Review 53: $452-465$.

Viton, P.A. (1995). Private roads. Journal of Urban Economics 37: 260-289.

Von Neumann, J., and Morgenstern, O. (1944). Theory of Games and Economic Behavior. Princetion University Press: Princetion, NJ.

Von Neumann, J. (1966) Theory of Self-Reproducing Automata. Edited by A. W. Burks. University of Illinois Press

Waddell (2001) UrbanSim: modeling urban development for land use, transportation, and environment planing. Paper presented to the $17^{\text {th }}$ Pacific Conference of the Regional Science Association, June 30-July4, 2001 
Walters, A. (1968). The Economics of Road User Charges. Baltimore: Johns Hopkins Press.

Wardrop, J.G. (1952) Some theoretical aspects of road traffic research. Proceedings of the Institution of Civil Engineers, Part II, 1(36): 325-62

Webster F.V, Bly, P.H., and N.J. Paulley (editors) (1988) Urban land use and transport interaction: Policies and models. The report of the International Study Group on Land Use/ Transport Interaction (ISGLUTI), Gower.

Williams, P.A. (1989) The Influence of Residential Accessibility on Household Trip Making. Socioeconomic Planning Sciences 23(6): 373-385.

Winston, C., and Shirley, C. (1998). Alternate route: Toward efficient urban transportation. The Brookings Institution, Washington, DC.

Wohl, M., and Hendrickson, C. (1984). Transportation Investment and Pricing Principles. John Wiley \& Sons, Inc.

Wolfram, S. (1994) Cellular Automata and Complexity. MA: Addison-Wesley.

Wolfram, S. (2002) A New Kind of Science. Champaign, IL: Wolfram Media.

Xin, W. and Levinson, D. (2006). Stochastic congestion and pricing model with endogenous departure time selection and heterogeneous travelers. Proceedings of 11th International Conference for Hong Kong Society of Transportation Studies, December 2006.

Yamins D., Rasmussen, S. and D. Fogel (2003) Growing urban roads. Networks and Spatial Economics 3: 69-85

Yang, H., Bell, M.G.H. (1998). Models and algorithms for road network design: a review and some new developments. Transport Review 18: 257-278. 
Yang, H., Tang, W.H., Cheung, W.M., and Meng, Q. (2002). Profitability and welfare gain of private toll roads in a network with heterogeneous users. Transportation Research 36A: $537-554$.

Yerra, B. and D. Levinson (2002) The emergence of hierarchy in Transportation networks. Under review Annals of Regional Science.

Zhang, L. (2006). Traffic diversion effect of ramp metering. Journal of the Transportation Research Board (In Press).

Zhang, L., and Levinson, D. (2004). Optimal freeway ramp control without origin-destination Information. Transportation Research 38B (10): 869-887.

Zhang, L., and Levinson, D. (2005). Balancing efficiency and equity of ramp meters. $A S C E$ Journal of Transportation Engineering 131 (6): 477-481.

Zhang, L., and Levinson, D. (2006). Ramp metering and freeway bottleneck capacity. Transportation Research A (Accepted for Publication).

Zhang, L., \& Levinson, D. (2007) The economics of transportation network growth. In Coto, P., \& I. Vicente (Eds.), Essays on Transportation Economics. Springer Science.

Zhang, L. (2008) Do freeway operations exacerbate urban sprawl? Transportation Geography (under review).

Zhang, L., and Levinson, D. (2008) An agent-based model of price competition and product differentiation on congested networks. Journal of Transportation Economics and Policy (forthcoming).

Zhang, L., and Levinson, D. (2006). The economics of transportation network growth. In Coto, P., and I. Vicente (Eds.), Essays on Transportation Economics. Springer Science.

Zhang, L., and Levinson, D. (2005) Road pricing with autonomous links. Journal of the 
Transportation Research Board 1932: 147-155.

Zhang, L., Developing a positive approach to travel demand forecasting: Theory and model. Traffic and Transportation Theory 17, London (Accepted for publication).

Zhang, L., and Levinson, D. (2004). An agent-based approach to travel demand forecasting: An exploratory analysis. Journal of the Transportation Research Board 1898: 28-36.

Zhang, L., and Levinson, D. (2005). Road pricing with autonomous links. Transportation Research Record: Journal of the Transportation Research Board 1932: 147-155.

Zhang, L. and, Levinson, D. (2003). A model of the rise and fall of roads. Presented at the $50^{\text {th }}$ North American Regional Science Council Annual Meeting, Nov 20-22, Philadelphia, PA.

Zhang, L., Xu, W., and Li, M. (2009). Co-evolution of land use and transportation. OTREC Project Final Report.

Zou, X and Levinson, D. (2006). A Multi-Agent Congestion and Pricing Model Transportmetrica Vol.2, No.3, 2006 pp. 237-249. 




\section{GOTREC \\ AND EDUCATION CONSORTIUM}

P.O. Box 751

Portland, OR 97207

OTREC is dedicated to stimulating and conducting collaborative multi-disciplinary research on multi-modal surface transportation issues, educating a diverse array of current practitioners and future leaders in the transportation field, and encouraging implementation of relevant research results. 